\title{
Flavonoids against non-physiologic inflammation attributed to cancer initiation, development, and progression-3PM pathways
}

\author{
Peter Kubatka ${ }^{1}$ Alena Mazurakova ${ }^{2} \cdot$ Marek Samec $^{3} \cdot$ Lenka Koklesova $^{2} \cdot$ Kevin Zhai $^{4} \cdot$ Raghad AL-Ishaq $^{4} \cdot$ \\ Karol Kajo ${ }^{5} \cdot$ Kamil Biringer $^{2} \cdot$ Desanka Vybohova $^{6} \cdot$ Aranka Brockmueller $^{7} \cdot$ Martin Pec $^{1} \cdot$ Mehdi Shakibaei $^{7}$. \\ Frank A. Giordano ${ }^{8}$. Dietrich Büsselberg ${ }^{4}$. Olga Golubnitschaja ${ }^{9}$
}

Received: 27 August 2021 / Accepted: 22 September 2021 / Published online: 6 October 2021

(c) The Author(s) 2021

\begin{abstract}
Inflammation is an essential pillar of the immune defense. On the other hand, chronic inflammation is considered a hallmark of cancer initiation and progression. Chronic inflammation demonstrates a potential to induce complex changes at molecular, cellular, and organ levels including but not restricted to the stagnation and impairment of healing processes, uncontrolled production of aggressive ROS/RNS, triggered DNA mutations and damage, compromised efficacy of the DNA repair machinery, significantly upregulated cytokine/chemokine release and associated patho-physiologic protein synthesis, activated signaling pathways involved in carcinogenesis and tumor progression, abnormal tissue remodeling, and created pre-metastatic niches, among others. The anti-inflammatory activities of flavonoids demonstrate clinically relevant potential as preventive and therapeutic agents to improve individual outcomes in diseases linked to the low-grade systemic and chronic inflammation, including cancers. To this end, flavonoids are potent modulators of pro-inflammatory gene expression being, therefore, of great interest as agents selectively suppressing molecular targets within pro-inflammatory pathways. This paper provides in-depth analysis of anti-inflammatory properties of flavonoids, highlights corresponding mechanisms and targeted molecular pathways, and proposes potential treatment models for multi-level cancer prevention in the framework of predictive, preventive, and personalized medicine (PPPM / 3PM). To this end, individualized profiling and patient stratification are essential for implementing targeted anti-inflammatory approaches. Most prominent examples are presented for the proposed application of flavonoid-conducted anti-inflammatory treatments in overall cancer management.
\end{abstract}

Keywords Natural substances $\cdot$ Phytochemicals $\cdot$ Flavonoids $\cdot$ ROS $\cdot$ DNA damage $\cdot$ Carcinogenesis $\cdot$ Inflammation $\cdot$ Lowgrade systemic inflammation - Cancer - Cancer initiation - Cancer promotion - Cancer progression - Systemic hypoxicishemic effects $\cdot$ Pre-metastatic niches $\cdot$ Impaired healing $\cdot$ Molecular targets $\cdot$ NF- $\mathrm{KB}$ signaling $\cdot$ Inflammatory pathway . HIF-1 $\alpha \cdot$ TNF- $\alpha \cdot$ Cytokines $\cdot$ IL-1 $\beta \cdot$ IL- $6 \cdot \mathrm{IL}-8 \cdot \mathrm{S} 100 \cdot$ Tissue remodeling $\cdot$ Matrix metalloproteinases $\cdot$ Predictive preventive personalized medicine (PPPM / 3PM)

\section{Abbreviations}

4EBP1

ACAN

ADAM

ADAMTS
Translation repressor protein

Aggrecan

Metalloproteinase domain-containing protein 12

Disintegrin and metalloproteinase with thrombospondin motifs
AKT

AMPK

AOM

AP-1

APR

Arg-1

Bad

BALP

Bax

Bcl-2

BMI

BM-MSC
Serine/threonine-protein kinase/protein kinase B

5' AMP-activated protein kinase

Azoxymethane

Activator protein 1

Acute phase response

Arginase 1

Bcl-2-associated agonist of cell death

Bone alkaline phosphatase

Bcl-2-associated X protein

B cell lymphoma 2

Body mass index

Bone marrow mesenchymal stem cells

Extended author information available on the last page of the article 


\begin{tabular}{|c|c|c|c|}
\hline BUB1 & $\begin{array}{l}\text { Mitotic checkpoint serine/threonine } \\
\text { kinase }\end{array}$ & IGF-1/IGF-1R & $\begin{array}{l}\text { Insulin-like growth factor } 1 / \text { insulin-like } \\
\text { growth factor type } 1 \text { receptor }\end{array}$ \\
\hline CAFs & Cancer-associated fibroblasts & IKK & Kappa kinase \\
\hline CAT & Catalase & IL & Interleukin \\
\hline CCL & $\mathrm{C}-\mathrm{C}$ motif chemokine ligand & ILK & Integrin-linked protein kinase \\
\hline CCNB2 & Cyclin B2 & iNOS & Inducible nitric oxide synthase \\
\hline $\mathrm{CD}$ & Cluster of differentiation & JAK & Janus kinase \\
\hline $\mathrm{CDC} 20$ & Cell division cycle 20 & JNK & c-Jun amino-terminal kinases \\
\hline CDK1 & Cyclin-dependent kinase 1 & Ki67 & Proliferative index \\
\hline c-FLIP ${ }_{L}$ & $\begin{array}{l}\text { FADD-like interleukin-1 beta-convert- } \\
\text { ing enzyme inhibitory protein }\end{array}$ & $\begin{array}{l}\text { LC3B } \\
\text { LCSLC }\end{array}$ & $\begin{array}{l}\text { Autophagy marker light chain } \\
\text { Liver cancer stem-like cells }\end{array}$ \\
\hline CINC-1 & $\begin{array}{l}\text { Cytokine-induced neutrophil } \\
\text { chemoattractant- } 1\end{array}$ & $\begin{array}{l}\text { LIF } \\
\text { LPS }\end{array}$ & $\begin{array}{l}\text { Leukemia inhibitory factor } \\
\text { Lipopolysaccharide }\end{array}$ \\
\hline $\begin{array}{l}\text { cMYC } \\
\text { COL2A1 }\end{array}$ & $\begin{array}{l}\text { Regulator gene and proto-oncogene } \\
\text { Collagen type II alpha } 1 \text { chain }\end{array}$ & Lyn & $\begin{array}{l}L Y N \text { proto-oncogene, Src family tyros- } \\
\text { ine kinase }\end{array}$ \\
\hline $\mathrm{COX}-2$ & Cyclooxygenase 2 & MAMs & Metastasis-associated macrophages \\
\hline $\mathrm{CSCs}$ & Cancer stem cells & MAPK & Mitogen-activated protein kinase \\
\hline CSE & Cigarette smoke extracts & Mcl-1 & $M C L 1$ apoptosis regulator, $\mathrm{Bcl}-2$ family \\
\hline CTX-II & $\begin{array}{l}\text { C-terminal cross-linked telopeptide of } \\
\text { type } I I \text { collagen }\end{array}$ & MCP-1 & $\begin{array}{l}\text { member } \\
\text { Monocyte chemoattractant protein-1 }\end{array}$ \\
\hline CX3CL1 & $\mathrm{C}-\mathrm{X} 3-\mathrm{C}$ motif chemokine ligand 1 & M-CSF & Macrophage colony-stimulating factor \\
\hline CXCL & $\mathrm{C}-\mathrm{X}-\mathrm{C}$ motif chemokine ligand & MDA & Malondialdehyde \\
\hline CXCR4 & $\mathrm{C}-\mathrm{X}$-C motif chemokine receptor 4 & MDSCs & Myeloid-derived suppressor cells \\
\hline DMBA & 7,12-Dimethylbenz(a)anthracene & MMPs & Matrix metalloproteinases \\
\hline DMH & 1,2-Dimethylhydrazine dihydrochloride & MPG & N-Methylpurine DNA glycosylase \\
\hline DSS & Dextran sulfate sodium & mTOR & Mechanistic target of rapamycin \\
\hline E2F5 & E2F transcription factor 5 & MYBL2 & MYB proto-oncogene like 2 \\
\hline ECM & Extracellular matrix & NADPH & Nicotinamide adenine dinucleotide \\
\hline EGCG & Epigallocatechin-3-gallate & & phosphate \\
\hline eIF4E & $\begin{array}{l}\text { Eukaryotic translation initiation factor } \\
4 \mathrm{E}\end{array}$ & $\mathrm{NF}-\kappa \mathrm{B}$ & $\begin{array}{l}\text { Nuclear factor kappa-light-chain- } \\
\text { enhancer of activated B cells }\end{array}$ \\
\hline $\begin{array}{l}\text { EMT } \\
\text { eNOS }\end{array}$ & $\begin{array}{l}\text { Epithelial-mesenchymal transition } \\
\text { Endothelial nitric oxide synthase }\end{array}$ & NLRP3 & $\begin{array}{l}\text { NOD-, LRR-, and pyrin domain-con- } \\
\text { taining protein } 3\end{array}$ \\
\hline ERK & Extracellular signal-regulated kinase & NOX2 & NADPH oxidase 2 \\
\hline ETV6-RUNX1 & $\begin{array}{l}\text { ETS variant transcription factor 6-runt- } \\
\text { related transcription factor } 1\end{array}$ & Nrf2 & $\begin{array}{l}\text { Nuclear factor erythroid 2-related factor } \\
2\end{array}$ \\
\hline FAK & Focal adhesion kinase & $\mathrm{OC}$ & Osteocalcin \\
\hline FGF2 & Fibroblast growth factor 2 & OPG & Osteoprotegerin \\
\hline FGFR2 & Fibroblast growth factor receptors & PARP & Poly (ADP-ribose) polymerase \\
\hline $\mathrm{G}-\mathrm{CSF}$ & Granulocyte colony-stimulating factor & PBO & Piperonyl butoxide \\
\hline GM-CSF & Granulocyte-macrophage colony-stimu- & PCNA & Proliferating cell nuclear antigen \\
\hline GSH & $\begin{array}{l}\text { lating factor } \\
\text { Glutathione }\end{array}$ & $\begin{array}{l}\text { PD-L1 } \\
\text { PGE2 }\end{array}$ & $\begin{array}{l}\text { Programmed death-ligand } 1 \\
\text { Prostaglandin E2 }\end{array}$ \\
\hline GTPs & Green tea polyphenols & PI3K & Phosphoinositide 3-kinase \\
\hline $\mathrm{HCC}$ & Hepatocellular carcinoma & PIGF & Placental growth factor \\
\hline HGF & Hepatocyte growth factor & PIINP & Human procollagen II N-terminal \\
\hline HIF- $1 \alpha$ & Hypoxia-inducible factor $1 \alpha$ & & propeptide \\
\hline Hs-CRP & High-sensitivity C-reactive protein & PIM2 & Pim-2 proto-oncogene, serine/threonine \\
\hline HSP90 & Heat shock protein 90 & & kinase \\
\hline $\begin{array}{l}\text { IBD } \\
\text { ICAM-1 }\end{array}$ & $\begin{array}{l}\text { Inflammatory bowel disease } \\
\text { Intercellular adhesion molecule } 1\end{array}$ & PPPM / 3PM & $\begin{array}{l}\text { Predictive, preventive, and personalized } \\
\text { medicine }\end{array}$ \\
\hline ID1 & Inhibitor of differentiation 1 & PTEN & Phosphatase and tensin homolog \\
\hline IFN- $\gamma$ & Interferon gamma & PTGER2 & Prostaglandin E receptor 2 \\
\hline
\end{tabular}


PTGS2 Prostaglandin-endoperoxide synthase 2

RANKL Receptor activator of nuclear factor- $\mathrm{kB}$ ligand

Rap1 Ras-related protein 1

ROS/RNS Reactive oxygen species/reactive nitrogen species

S100A7/RAGE Receptor for advanced glycation end products

S6K1

SAA

SHP-1

Slug

Smad4

Snail

SOD

Sox 2

Src

STAT3

Syk

TAMs

TANs

TGF- $\beta$

Th17s

TIMP1

TLR4

TME

TNF- $\alpha$

TPA

TRAIL

Tregs

Twist

UV

VCAM-1

VEGF

VEGFR2

WCE

YAP

ZEB 1

\section{Introduction}

Inflammation is a physiological process necessary for homeostasis. Inflammation plays an elementary role in host defense against various pathogens through the activation and recruitment of immune cells and the consequent actions of innate and adaptive immunity. It is imperative for processes such as tissue regeneration, repair, and remodeling. Furthermore, its subtle manifestations are essential for the modulation of tissue homeostasis [1]. Cancer cells frequently secrete several growth factors that stimulate myelopoiesis and recruit myeloid cells to TME. Therefore, the TMEs of various cancers are characterized by the high infiltration of monocytes, macrophages, granulocytes, and dendritic cells. Most myeloid cells within TMEs are present in an immature form; however, cancer-derived growth factors modify these myeloid cells into cells that support carcinogenesis by enhancing proliferation, migration, and metastasis and enabling cancer cell survival and immune evasion [2].

Acquired data from the oncology research is applicable in the novel clinical trend focused on 3PM strategies considered as the medicine of the future [3,4]. The presence of inflammatory or immune cells in specific tissues/organs was evaluated as a predictive marker in cancer therapy. Longterm oncology research indicates that chronic inflammation is associated with increased cancer risk and worsened disease prognosis [5]. Controlled inflammatory processes include specific immune responses-mainly linked with the maturation of antigen-presenting cells that promote tissue/ organ healing. On the other hand, amplified, uncontrolled, or prolonged inflammation associated with immunosuppression is linked with many pathologies, including carcinogenesis [6]. It is widely accepted that up to $25 \%$ of neoplasms in humans are associated with chronic inflammation induced by viral and/or bacterial infections, physical and/or chemical stimuli, or metabolic pathologies [6-8]. Chronic inflammation influences tumor initiation and development by modulating critical signaling pathways associated with cellular transformation, proliferation, angiogenesis, survival, invasion, and metastasis [9]. The inflammation that initiates carcinogenesis exists long before cancer appears. In this regard, conditions such as chronic hepatitis, Helicobacter-induced gastritis, inflammatory bowel disease, and schistostomainduced bladder inflammation increase the risk of several cancers, such as liver cancer, stomach cancer, colorectal cancer, and bladder cancer [8]. Numerous environmental factors must be considered, as they initiate and/or promote carcinogenesis by inducing organ-specific or systemic chronic inflammation. For instance, asbestos and tobacco smoke can induce lung and airway inflammation and thus initiate mesothelioma and lung carcinoma [10].

Similarly, low-grade systemic inflammation induced by hyperglycemia, hyperlipidemia, and obesity is a risk factor for several cancers, such as liver, pancreatic, colon, and breast cancers [11]. Abundant scientific evidence points out a significant role of systemic inflammation in cancer initiation, development, and progression. Obesity-, tobacco smoke-, and bacterial product-induced inflammation stimulates neutrophils and causes extracellular trap formation; these processes initiate cancer invasion [12]. The 
evaluation and modulation of the biological balance between controlled inflammation and uncontrolled chronic inflammation are essential for cancer prediction, prognostication, and prevention.

In the search for novel therapeutic agents that can precisely modulate cancer-associated inflammation, plantderived natural products hold great promise due to their multi-targeting modes of action. Plant-derived compounds potently modulate inflammation. In the past several decades, many studies reported the anti-inflammatory effects of various phytochemicals in vitro and in vivo. In this regard, flavonoids could directly modulate the immune system [13]. Flavonoids exert anti-inflammatory actions through the regulation of immune cells, suppression of pro-inflammatory transcription factors, chemokines, cytokines, and COX-2, and inhibition of PI3K/AKT and IKK/JNK $[14,15]$.

This article summarizes the most recent evidence regarding the role of flavonoids as suppressors of pro-inflammatory cell signaling pathways that can promote carcinogenesis. The evidence supports the preventive and therapeutic potential of flavonoids in cancer.

\section{The role of chronic inflammation in different stages of carcinogenesis}

\section{Cancer initiation}

Two main cellular events are necessary for cancer initiation: first, the accumulation of genetic and/or epigenetic changes in genes that control tumor suppression/oncogenic signaling pathways; and second, the formation of transformed and/ or malignant clones. A qualitative change into a tumor follows; the pro-inflammatory microenvironment can significantly support this process. A prolonged pro-inflammatory microenvironment contributes to genomic instability and cancer initiation. Therefore, pathogenic infections lead to DNA damage and/or cellular metabolic deregulation and thus change genomic integrity. The TME could trigger the recruitment of pro-inflammatory cells, making the environment rich in chemokines, growth factors, cytokines, and DNA-damaging agents (ROS, RNS) that activate DNA damage response pathways. Long-term deregulation of these factors may cause abnormalities and related pathologies, including cancer [16]. Moreover, the adaptive nature of carcinogenesis is highlighted because cell clones with equal genetic changes have different propensities for development and survival. These processes are strongly affected by the TMEs of these clones [17].

Chronic inflammatory processes are associated with oxidative/nitrosative stress, and consequent electron "storms" in cells/tissues induce progressive DNA damage. ROS/RNS originate from the immune system via specific NADPH oxidases that are crucial for pathogen clearance [18]. These DNA changes are linked with the deregulation of cellular homeostasis and result in genetic aberrations that act as initiation factors in chronic inflammation-induced pathogenesis, including carcinogenesis [19]. For example, chronic inflammation and ROS generation in colon epithelial cells can affect the $\mathrm{Wnt} / \beta$-catenin and/or base excision repair pathways and thus increase the risk of polyp formation. The combination of DNA damage caused by oxidative stress and errors in DNA polymerase activity can support $\mathrm{C}>\mathrm{T}$ transitions in various tissues, leading to a hypermutated cellular phenotype [20]. In another study using an inflammatory colorectal cancer model, the EMT factor ZEB1 promoted inflammation and progression towards inflammation-driven carcinoma by suppressing the DNA repair glycosylase MPG in epithelial cells [21]. Gobert et al. (2017) reported that polyamine- and NADPH-dependent ROS generation during Helicobacter pylori infections might lead to the initiation of inflammation and consequent carcinogenesis [22].

During chronic inflammation, pro-inflammatory mediators are continuously produced. Cytokines, growth factors, and acute-phase proteins, all part of the TME modulate the inflammatory responses and the crosstalk between signaling pathways involved in cancer initiation. Several papers describe the key role of the pro-inflammatory microenvironment in tumor initiation. Following infection or injury, SAA represents a critical acute phase protein secreted by hepatocytes during the APR. Autophagy is reported to be critical in tumors-both pro- and anti-carcinogenic. High levels of SAA in the TME contribute to carcinogenesis. SAA affects cell-signaling pathways, such as those associated with PI3K and MAPK, which modulate autophagy. Dysregulation of autophagy can initiate the transformation of normal cells to premalignant via metabolic stress, DNA damage, oxidative stress, and endoplasmic reticulum stress. In addition, autophagy can support the survival of transformed cells [23]. For instance, the type A receptor of IL-17 directly triggers pro-carcinogenic signaling in transformed enterocytes.

Moreover, the type A receptor of IL-17 stimulates ERK, p38 MAPK, and NF- $\kappa B$ signaling and induces the proliferation of transformed enterocytes that lack APC tumor suppressor functions [24]. Beneforti et al. (2020) hypothesized that infections and inflammation are the most important triggers of mutation accumulation in and the malignant transformation of ETV6-RUNX1 fusion gene $\left(\mathrm{E} / \mathrm{R}^{+}\right)$preleukemic cells in childhood acute lymphoblastic leukemia. The authors showed that the pro-inflammatory cytokines IL-6/TNF- $\alpha /$ IL- $1 \beta$ coact with BM-MSC in promoting the emergence of $E / R^{+} \mathrm{Ba} / \mathrm{F} 3$ cells (a murine IL-3-dependent pro-B cell line) and modulating their survival and proliferation. In addition, BM-MSCs attracted $\mathrm{E} / \mathrm{R}^{+} \mathrm{Ba} / \mathrm{F} 3$ cells in a chemokine type 2 receptor-dependent manner; $\mathrm{E} / \mathrm{R}^{+}$ human $\mathrm{CD}_{34}{ }^{+} \mathrm{IL}_{7} \mathrm{R}^{+}$progenitors (a supposed population 
of cells for acute lymphoblastic leukemia) were protected in the presence of BM-MSC and IL-6/TNF- $\alpha / \mathrm{IL}-1 \beta$. The authors concluded that DNA damage accumulation depends on the extent of inflammation in both control and $\mathrm{E} / \mathrm{R}^{+} \mathrm{Ba} /$ F3 cells and might lead to the transformation of the apoptosis-resistant pre-leukemic clones [25]. Furthermore, Huang et al. (2020) found that IL-1 $\beta$, secreted by macrophages stimulated by multi-walled carbon nanotubes, increased the release of pro-inflammatory cytokines such as TNF- $\alpha$, IL-8, and IL- 6 from mesothelial cells. The authors concluded that inflammation-induced NF- $\mathrm{BB}$ (p65)/IL-6/STAT3 signaling plays a crucial role in the malignant transformation of pleural mesothelial cells [26].

Different cytokines and chemokines may modulate the conversion of normal fibroblasts into CAFs. CAFs synthesize pro-inflammatory cytokines such as IL- 6 and LIF, which in turn modulate their epigenetic status. This activity promotes the pro-tumorigenic function of CAFs by enhancing actomyosin contractility and ECM remodeling [27]. IL-1 $\beta$ is another pro-inflammatory cytokine that initiates carcinogenesis and promotes immunosuppression. These functions of IL- $1 \beta$ are mainly observed in the early stages of carcinogenesis; moreover, its expression significantly impacts the process of malignant transformation [28].

\section{Cancer promotion}

Like cancer initiation, a pro-inflammatory TME and consequent signaling can support numerous growth factors in promoting carcinogenesis. Cancer promotion can be regulated by several pathways associated with inflammation, such as those involving NF- $\mathrm{KB}$, STAT3, mTOR, and MAPKs, which are triggered by pro-inflammatory cytokines like IL-6, TNF$\alpha$, and IL-1 $\beta$ [29]. Ju et al. (2020) revealed that infiltrated macrophages released TNF- $\alpha$ and IL-6, which induced the expression of PD-L1 in cancer cells. Consequently, TNF- $\alpha$ and IL- 6 triggered the activation of the NF- $\mathrm{\kappa B}$ and STAT3 signaling pathways to modulate PD-L1 expression. The authors concluded that macrophage-induced increases in PD-L1 expression could allow cancer cells to escape from cytotoxic T cell surveillance and proliferate [30]. PIM2 is an oncomarker highly expressed in HCC which correlates with poor prognosis. Functional studies demonstrated that PIM2 is an enhancer of cell proliferation, cell motility, angiogenesis, and chemoresistance in cancer. In this regard, HCC cells treated with TNF- $\alpha$ showed increased PIM2 expression; this consequently increased the expression of TNF- $\alpha$. The same study revealed that PIM2 promotes HCC carcinogenesis by activating the NF- $\mathrm{KB}$ signaling pathway through PIM2 receptor phosphorylation [31].

S100A7/RAGE signaling in adjacent endothelial cells may behave as a crucial angiocrine effector. Muoio et al. (2021) found that IGF-1/IGF-1R signaling increases STAT3 activation in breast cancer cells. Consequently, activating the S100A7/RAGE pathway via STAT3 signaling sustains angiogenesis and thus stimulates cancer promotion in breast cells [32]. The upregulation of cancer-promoting inflammatory cytokines (host and tumor-secreted), such as NF- $\mathrm{KB}$, COX-2, IL-1, IL-6, TNF- $\alpha$, and IFN- $\gamma$, is strongly associated with STAT3 and AKT signaling activation in oral squamous cell carcinoma in vitro. The suppression of these cytokines may decrease tissue inflammation and thus decrease the proliferation of oral squamous cell carcinoma cells [33]. TAMs play a substantial role in modulating the interactions between cancer cells and the immune system. In this regard, the TAM microenvironment promoted the growth of triplenegative breast cancer cells in a study by Deng et al. (2021). The authors described that TAMs promoted the growth of MDA-MB-231 and MDA-MB-468 cells by upregulating the IL-10/STAT3/PD-L1 immunosuppressive signaling pathway [34]. Zhang et al. (2017) revealed that TAMs might trigger PD-L1 expression by producing IFN- $\gamma$ via the JAK/STAT3 and PI3K/AKT signaling cascades in A549 cells [35].

Recent data revealed that MAPK upregulation is crucial in modulating inflammation-associated cancer development. MAPKs include p38 MAPK, JNK, and ERK. These enzymes are serine-threonine protein kinases that affect essential cellular activities, such as proliferation, differentiation, apoptosis, survival, inflammation, and innate immunity. The described enzymes are upregulated by various types of cellular stress and pro-inflammatory cytokines such as TNF- $\alpha$ and IL-1 $\beta$ [36]. In addition, increased p38 MAPK signaling is linked with increased proliferation and decreased apoptosis of colon and liver cancer cells. Deregulation of the mTOR signaling pathway, including the loss of PTEN function, amplification/mutation of $P I 3 K$, and overexpression of S6K1, 4EBP1, eIF4E, and AKT, was described in multiple cancer types but mainly in melanoma [37]. In a preclinical study, lung cancer-induced osteoclastogenesis in vitro was associated with the upregulation of IL- 6 and TNF- $\alpha$ and consequent activation of the AMPK/mTOR signaling pathway [38].

\section{Cancer progression}

Cancer metastasis is a highly inefficient process. Most cancer cells released from the primary tumor site die before creating a distant metastatic site. To further improve the ratio of dead cancer cells with invasive phenotypes, it is possible to modulate specific "key steps" within the complex process of tumor progression that may decrease the "success" of metastatic invasion and improve patient survival. Metastasis begins with the invasion of tumor cells from the epithelium into the surrounding tissues and the concurrent EMT. The post-EMT phenotype of cells (often only partial) allows them to cross the basal epithelial membrane and 
reach lymphatic and/or blood capillaries [8, 39]. A recent study described a novel lymphatic pattern in the hypoxic TME, wherein TAMs encapsulate lymphatic vessels to form an interconnected network. These aggregates are advantageous for and actively involved in early lymph node metastasis [40].

Moreover, research data revealed the importance of the pro-inflammatory TME within the ECM in modulating tumor-associated processes such as invasion, metastasis, angiogenesis, immune cell modulation, and therapeutic resistance [41]. Calon et al. (2015) reported that all colorectal cancer subtypes with poor prognosis are characterized by stromal cancer cells with a TGF- $\beta$-triggered transcription program associated with a pro-inflammatory TME. The application of TGF- $\beta$ signaling inhibitors suppressed the crosstalk between the TME and cells and thus suppressed cancer progression in patient-derived tumor organoids and xenografts [42].

CSCs are more effective in metastasis than other (bulk) tumor cells. CSCs are essential for cancer metastasis and therapeutic resistance. Numerous stimuli such as chronic inflammatory signaling, including the activation of the STAT3 and NF- $\mathrm{BB}$ transcription factors, may drive the stemness of CSCs in cancer tissue and enlarge their proportion within the cell population, thereby increasing the potential of metastasis. Importantly, CSCs are functionally and transcriptionally more related to mesenchymal cells than bulk tumor or normal epithelial cells [43]. Cytokines and chemokines, both their receptors and signaling pathways, are essential factors in the complex interplay and crosstalk between different cell types and secreted factors in the events that lead to cancer metastasis. Numerous cytokines and chemokines, such as TNF, IL-6, IL-8, CXCL12, TGF$\beta$, CXCL8, VEGF, RANKL, CCL2, CX3CL1, IL-1, IL-7, CXCL1, and CXCL16, contribute to the regulation of cancer metastasis [44, 45].

Moreover, comprehensive data support the role of a proinflammatory TME in the promotion of CSCs. Cytokines and chemokines may benefit cancer cells and/or CSCs in processes such as cell proliferation, survival, and migration [46]. In this regard, there exists a close linkage between CSCs and inflammatory components, i.e., inflammatory cells such as TAMs and MDSCs and inflammatory cytokines (TNF, IL-6, IL-17, IFNs) [47].

Metastatic spread typically occurs through blood and lymphatic vessels. Therefore, intravasation and extravasation are essential processes in cancer metastasis. These processes are modulated by specific adhesion molecules and integrins facilitating cell-cell interactions/adhesion and cell movement. In this regard, inflammatory cytokines are important inducers of integrins, selectins, and adhesion molecules, such as VCAM-1 and ICAM-1. In addition, TAMs produce pro-angiogenic growth factors and MMPs. Therefore, they support vasculogenesis and consequently the supply of oxygen and nutrients to solid tumors [48]. A preclinical study by Horiguchi et al. (2020) demonstrated that local inflammation, characterized by elevated IL-6, TNF- $\alpha$, and HGF in the bronchoalveolar lavage fluid, increased the metastatic activity of NL-17 cells in the lung. A pro-inflammatory TME significantly upregulated the expression of $\alpha 2$ integrin, VCAM-1, and ICAM-1. An anti-ICAM-1 antibody suppressed the invasive activity of NL-17 cells; therefore, adhesion molecules have a potential role in lung metastasis enhanced by local inflammation [49].

Comprehensive research has described specific cellular and molecular events that may cause tumor cells to escape immune surveillance, including those involving tumorinduced myeloid cell-mediated immunosuppression [50]. Multiple studies indicate that tumor-infiltrating myeloid cells accelerate cancer growth and support angiogenesis, metastasis, and therapeutic resistance after their conversion into potent immunosuppressive cells. Host and tumor cells in the TME secrete pro-inflammatory molecules that stimulate MDSCs and trigger their accumulation and suppressive activities [51]. Several mechanisms driven by MDSCs suppress $\mathrm{T}$ cells and activate immunosuppressive cell populations. Such inflammatory modulation in the TME causes the immune system to tolerate cancer cells and enhance their growth.

In conclusion, the interruption of the interplay between pro-inflammatory cytokines and pro-inflammatory/procarcinogenic cell signaling pathways affects all stages of carcinogenesis and might therefore represent a promising strategy in oncology research and practice.

\section{Anti-inflammatory activities of flavonoids: implications in carcinogenesis}

Flavonoids constitute a group of natural substances with different phenolic structures. They are found in fruits, vegetables, grains, flowers, tea, bark, roots, and stems. These natural molecules have well-described beneficial health effects in humans. Due to their anti-oxidative, anti-inflammatory, anti-mutagenic, anti-carcinogenic, and cellular enzyme modulating activities, flavonoids have numerous medicinal, pharmaceutical, and cosmetic applications. A substantial proportion of non-infectious diseases develops or is worsened by the chronic inflammatory process. Flavonoids are reported to combat most inflammatory processes underlying chronic conditions such as carcinogenesis [52-61].

\section{Cancer initiation}

Pro-inflammatory cytokine production and consequent intracellular ROS and RNS accumulation lead to DNA damage 
and initiate carcinogenesis. Flavonoids, as antioxidants, inhibit regulatory enzymes and transcription factors important for controlling inflammatory mediators. Moreover, they modulate cellular oxidative stress by interacting with DNA and enhancing genomic stability [62]. Flavonoids can inhibit DNA adduct formation, enhance DNA repair by interfering with genotype damage caused by the upregulation of phase II enzymes, and modify relevant signaling pathways [63]. It is well documented that specific flavonoids can reduce cytokine production; therefore, they may have preventive and therapeutic potential in inflammation-related diseases (such as cancer) [64]. TNF- $\alpha$ triggers the release of chemotactic proteins, e.g., MCP-1/CCL2. These regulatory molecules direct the infiltration and migration of TAMs, MDSCs, Tregs, TANs, Th17s, MAMs, and CAFs. Specific flavonoids can attenuate the TNF- $\alpha$-induced release of MCP-1/CCL2 and various recruiting cytokines from cancer cells [65, 66]. In addition, by targeting TGF- $\beta 2$, flavonoids suppress the cancer cell-mediated differentiation of naive fibroblasts into cancer-associated fibroblasts [67].

\section{Cancer promotion}

The inhibitory effect of flavonoids on cell proliferation and thus cancer promotion is associated with decreased phosphorylation of STAT-induced signaling pathway components and related transcriptional activators. Hou et al. (2019) revealed that flavonoid treatment inhibits recurring colitis and colitis-associated tumorigenesis; these flavonoids downregulate IL- $1 \beta$ and TNF- $\alpha$ and consequently inhibit inflammation-induced colorectal cancer in vitro [68]. NF-кB signaling plays a crucial role in inflammation and cancer growth. Flavonoids negatively regulate the NF- $\kappa \mathrm{B}$ signaling pathway by suppressing kinase phosphorylation, inhibiting $\mathrm{NF}-\kappa \mathrm{B}$ translocation into the nucleus, and blocking interactions between DNA and NF- $\mathrm{kB}$. Through these mechanisms, flavonoids inhibit inflammatory cascades associated with decreased cell proliferation, apoptotic induction, and the suppression of vasculogenesis [69]. In addition, flavonoids are promising anti-cancer agents that target the inflammatory PI3K/AKT/mTOR/p70S6K and ERK/MAPK signaling pathways $[70,71]$.

\section{Cancer progression}

Flavonoids exert chemopreventive effects by protecting against cancer progression, inhibiting CSC formation, and alleviating lung metastasis in a preclinical model [72]. The reduction in cancer metastasis was associated with regulating the PI3K/AKT, MAPK/ERK, and STAT3 pathwayscentral CSC-associated inflammatory signaling cascades. In another study, natural mixtures of flavonoids significantly downregulated the pro-inflammatory cytokines COX-2,
iNOS, and TNF- $\alpha$ and the pro-angiogenic factors VEGF and eNOS, and induced apoptosis by increasing the Bax/ Bcl-2 ratio in vitro [73]. In this regard, flavonoids are antiinflammatory agents that downregulate crucial modulators of advanced stages of cancer such as IL-1 $\beta$, IL-6, IL-10, TNF- $\alpha$, NF- $\kappa \beta$, NOS2, PTGS2, PTGER2, ACAN, COL2A1, MMP1, MMP13, ADAMTS4, ADAMTS5, and TIMP1. These changes correlated with the reduction of serum levels of PGE2, CTX-II, TNF- $\alpha$, MMP1, MMP13, PIINP, OPG, RANKL, OC, and BALP in a rat model [74]. Another study found that flavonoids exert their anti-metastatic activities by reducing CXCR 4 expression and can therefore support the blockade of cancer promotion [75]. Furthermore, flavonoids target the integrin-modulated ILK/YAP pathway and block the EMT and metastasis [76]. Moreover, flavonoids block angiogenesis and metastasis by suppressing VEGFinduced oxidative stress and NF- $\mathrm{\kappa B}$ signaling and downregulating adhesion molecules such as VCAM-1, ICAM-1, and E-selectin; these activities decrease the formation of new blood capillaries in cancer tissue [77]. Finally, MDSC activation is involved in chronic inflammation-related immunosuppression and $\mathrm{CD} 4^{+} / \mathrm{CD}^{+} \mathrm{T}$ cell activation through the ERK/IL-6/STAT3 and Arg-1/iNOS/Nox2/NF-kB/STAT3 signaling pathways. In this regard, flavonoids attenuate MDSC-mediated immunosuppression that is crucial for cancer growth and metastasis [78, 79].

\section{Flavonoids prevent tumor initiation by modulating inflammatory processes}

The concept of cancer chemoprevention by flavonoids was investigated in numerous in vivo and in vitro studies [80-84]. These natural phenolic compounds can modulate different steps of carcinogenesis [85]. As mentioned above, chronic inflammation accelerates genetic/epigenetic aberrations that lead to cancer initiation, promotion, and progression [86]. Prolonged chronic inflammation associated with the overexpression of inflammatory mediators in the cell microenvironment is a critical step that promotes cancer initiation [87]. The anti-inflammatory properties of flavonoids could prevent, suppress, and reverse cancer initiation [88, 89]. In the following section of the manuscript, we provide an overview of recent studies that analyze the role of flavonoids in tumor initiation through the modulation of inflammatory responses in vitro and in vivo.

\section{Preclinical research}

Baicalin, a flavonoid isolated from the roots of Scutellaria baicalensis, exerts different oncostatic effects [90, 91]. ROS generation due to constant UV-A exposure causes the formation of inflammatory products and the accumulation of 
DNA mutations [92]. The protective role of baicalin was investigated in an animal study that analyzed the association between UV-A irradiation, ROS production, and inflammation. The acquired data revealed that baicalin protects against UV-A-induced inflammation and oxidative damage by increasing IL-12 and IL-23. These effects are likely mediated by suppressing the TLR4 pathway, which has a significant role in inflammation [93]. Additionally, baicalin can be transformed into baicalein by intestinal microbiota. The anti-inflammatory and anti-cancer effects of baicalein were evaluated in an animal model of colorectal cancer. The authors used a gut-specific C57BL/6J Apc ${ }^{\mathrm{Min} /+} / \mathrm{J}$ mouse model (APC gene mutants) to evaluate parameters such as life span, tumor multiplicity, and organ index. Moreover, the expression of inflammatory cytokines was measured. Baicalein administration $(30 \mathrm{mg} / \mathrm{kg} /$ day $)$ decreased the number of tumors in the small intestine and colon (after 10 weeks of supplementation by baicalein) compared to controls. In addition, baicalein administration suppressed the expression of pro-inflammatory cytokines (IL-1 $\beta$, IL-2, IL-6, IL-10, GM-CSF, and G-CSF) [94]. Ulcerative colitis is classified as a chronic idiopathic IBD [95]. Patients with IBDs are at increased risk for the development of extra-intestinal malignancies [96]. Rutin is a naturally occurring flavonoid with profound effects on different cellular processes associated with a pathological phenotype [97]. As demonstrated in a DSS-induced experimental colitis model in vivo, rutin modulated the expression of pro-inflammatory genes. Rutin administration significantly suppressed the protein level of IL- $1 \beta$ and the expression of $I L-1 \beta$ and $I L-6$ mRNA in the colonic mucosa of mice. Moreover, rutin attenuated DSS-induced colitis symptoms, including weight loss and colorectal shortening, and improved the histological score of colitis in the tested animals [98]. Another flavonoid, myricetin, downregulates inflammatory factors including TNF- $\alpha$, IL-6, IL-1 $\beta$, NF- $\kappa B$, p-NF- $\kappa B$, PCNA, COX-2, and cyclin D1 in AOM/DSS-induced colitis in mice. Myricetin significantly reduced the number of colorectal tumors and decreased the size of polyps in the colon [99]. Furthermore, naringin prevented AOM/DSS-induced colitis and carcinogenesis in mice by suppressing MDSCs. A deeper analysis identified the downregulation of GM-CSF/M-CSF, IL-6, and TNF- $\alpha$ and the inhibition of the NF- $\mathrm{kB} / \mathrm{IL}-6 / \mathrm{STAT} 3$ pathway as further contributors to colitis-associated cancer [100].

Chronic arsenic exposure is associated with inflammation that could initiate carcinogenesis [101]. EGCG, a natural compound isolated from green tea, is a potent anti-inflammatory molecule [102]. EGCG exhibited an anti-inflammatory effect against arsenic $\left(\mathrm{NaAsO}_{2}\right)$-induced inflammation in mice. The acquired data revealed that EGCG administration downregulated the pro-inflammatory cytokines IL-1 $\beta$, IL- 6 , and TNF- $\alpha$. Additionally, EGCG attenuated oxidative stress by upregulating markers such as CAT, SOD, and GSH and decreasing MDA content in mice [103]. Furthermore, the administration of GTPs influenced UV-B-induced tumor development in mice. Likewise, UV-B is strongly associated with chronic inflammation and, as mentioned above, there is a strong relationship between UV radiation-induced chronic inflammation and skin carcinogenesis. GTPs suppressed the pro-inflammatory markers COX-2, PGE2, PCNA, and cyclin D1. Furthermore, levels of the pro-inflammatory cytokines TNF- $\alpha$, IL- 6 , and IL- $1 \beta$ were reduced after GTP administration [104]. Chronic gastritis and peptic ulceration-chronic inflammatory disorders caused by Helicobacter pylori infection-are strongly associated with an increased risk of cancer development $[105,106]$. The isoflavonoid genistein exerted anti-inflammatory effects in rats infected by Helicobacter pylori. Its anti-inflammatory properties were mediated by suppressing pro-inflammatory mediators such as TNF- $\alpha$ and CINC-1, NF- $\kappa \mathrm{B}$, and bacterial infection-induced gastric epithelial cell apoptosis [107]. Hesperidin, a flavone extracted from citrus fruits, has many biological effects [108]. Its impact on ulcerative colitis was documented in a study that evaluated the anti-inflammatory effect of hesperidin methyl chalcone in an animal model of acetic acid-induced colitis. As demonstrated above, chronic inflammation promotes colitis-associated cancer; thus, the attenuation of pro-inflammatory cytokines is a promising way to suppress cancer initiation [109]. Hesperidin significantly catalyzed colon antioxidant processes and suppressed pro-inflammatory cytokines (IL-33, IL-1 $\beta$, IL-6, and TNF- $\alpha$ ) in vivo [110]. In addition, quercetin exhibited anti-inflammatory effects in another model of DSS-induced experimental colitis in vivo. Comalada et al. (2005) evaluated the effect of quercitrin, a glycoside of quercetin that is cleaved by gut microbiota to generate quercetin. Quercetin significantly inhibited cytokine (IL- $1 \beta$ and TNF- $\alpha$ ) production and induced the expression of iNOS by downregulating the NF- $\kappa B$ pathway [111]. Moreover, the flavonoid luteolin possesses various beneficial properties for human health [112-114]. Luteolin significantly reduced malignant transformation induced by hexavalent chromium [Cr(VI)] in human bronchial epithelial cells (BEAS-2B). Recurrent exposure to $[\mathrm{Cr}(\mathrm{VI})]$ is connected to persistent inflammation and subsequent carcinogenesis [115]. Noteworthy, luteolin is known to downregulate AP-1, HIF- $1 \alpha, \mathrm{COX}-2$, and iNOS. In addition, luteolin prevented the transformation of BEAS2B into malignant phenotypes. The obtained data revealed decreases in IL- $1 \beta$, IL- 6 , IL- 8 , and TNF- $\alpha$ levels. Western blotting uncovered the inhibition of products associated with inflammation, including MAPK, NF-кB, COX-2, STAT-3, and iNOS in chronic [Cr(VI)]-exposed cells. In addition, luteolin reduced tumor incidence in mice injected with [Cr(VI)]-exposed BEAS-2B cells [116]. Furthermore, cigarette smoke modulates inflammation and induces chronic 
inflammation. Therefore, Pace et al. (2019) evaluated the impact of CSE on normal (16HBE) and cancerous (A549) epithelial cells. The study authors applied the naturally occurring flavone apigenin, which reduced miR-21 and IL-8 gene expression in both cell lines [117].

As we described in this chapter, flavonoids possess pleiotropic abilities in preventing cancer initiation through the suppression of chronic inflammation. The health benefits of flavonoids targeting inflammatory pathways identified in experimental studies could be translated into the clinical area. The investigation of novel therapeutic approaches to reverse and prevent cancer initiation through the modulation of chronic inflammation falls within the concept of 3PM. Table 1 summarizes the effects of flavonoids on molecular cascades associated with inflammation and subsequent carcinogenesis.

\section{Flavonoids as anti-inflammatory agents against tumor promotion in carcinogenesis}

\section{Isolated flavonoids in preclinical studies}

Chronic inflammation predisposes to cancer development and subsequently promotes all stages of tumorigenesis [8]. The anti-inflammatory and other anti-cancer effects of flavonoids were evaluated in cancer research since the last century. GTPs, silymarin, and apigenin inhibited skin tumor promotion by decreasing skin papilloma formation in DMBA-induced and TPA-promoted SENCAR mice [118-120].

As discussed above, various signaling pathways are associated with chronic inflammation, including the MAPK, AKT, mTOR, STAT3, and/or NF-кB pathways, and can potentially lead to tumor promotion. Therefore, in the twenty-first century, studies emphasize the precise molecular mechanisms and signaling pathways leveraged by flavonoids against inflammation in various stages of carcinogenesis.

Quercetin inhibited the PI3K/AKT/mTOR, Wnt $/ \beta$ catenin, and STAT3 signaling pathways in BC3, BCBL1, and $\mathrm{BC} 1$ primary effusion lymphoma cells. Further, quercetin inhibited tumor promotion by downregulating the proinflammatory cytokines IL-6 and IL-10; pro-survival molecules downstream of PI3K/AKT/mTOR, Wnt/ $\beta$-catenin, and STAT3 such as c-FLIP ${ }_{\mathrm{L}}$; and molecules linked to cell proliferation, including cyclin D1 and cMyc [121].

Moreover, icaritin from a Chinese herbal medicine (Epimedium species) inhibited proliferation and tumor growth and induced apoptosis of K562 and primary chronic myeloid leukemia cells. A mouse model also revealed that icaritin modulates signaling pathways associated with chronic inflammation such as MAPK/ERK/JNK and JAK2/ STAT3/AKT by upregulating p-JNK and p-C-JUN and downregulating p-ERK, p-P38, JAK-2, p-JNK, p-STAT3, and p-AKT in a dose- and time-dependent manner [122].

Furthermore, fisetin suppressed the expression of inflammatory mediators and ICAM-1 in IL-1 $\beta$-promoted inflammation in A549 lung adenocarcinoma cells. Further, administrating fisetin downregulates COX-2, PGE2, IL-8, CCL5, MCP-1, TNF- $\alpha$, and IL-6. Moreover, fisetin exerted antiinflammatory effects through the suppression of the NF- $\mathrm{KB}$ and ERK1/2 signaling pathways in IL- $1 \beta$-stimulated A549 cells, suggesting to prevent tumor promotion [123]. In another study, fisetin induced apoptosis by increasing caspase- 3 expression and regulating the inflammatory PI3K/ AKT/NF- $\mathrm{KB}$ signaling pathway in TU212 head and neck squamous cell carcinoma cells. Further, the suppression of TU212 cell proliferation and consequent changes in the tumor volume and weight of nude mice after fisetin treatment were connected to decreased Ki67 levels and the inactivation of ERK1/2- and PI3K/AKT-regulated mTOR [124]. Additionally, the combination of fisetin with carnosic acid enhanced their anti-inflammatory effects against tumor promotion of HCC 827 and $\mathrm{H} 358$ human lung cancer cell lines and their murine xenografts. Co-treatment of fisetin and carnosic acid induced apoptosis by upregulating caspase-3, Bax and Bad, and death receptor of TRAIL, and downregulating the anti-apoptotic Bcl-2 and Bcl-xl proteins [125].

Interestingly, luteolin inhibited U251 and LN229 glioma cell proliferation through the induction of apoptosis. The apoptosis of U251 and LN229 cells was mediated by the anti-inflammatory effects of luteolin and associated activation of MAPKs (JNK, ERK, and p38) and death receptors (FADD) that regulated apoptotic proteins (caspase-8, caspase-3, and PARP). Further, luteolin promoted cell autophagy by upregulating LC3B II/I and downregulating p62 [126]. Moreover, luteolin reduced the expression of the STAT3 signaling pathway target gene Mcl-1, Survivin, and Bcl-xl-downregulation of which reduced inflammation in SGC7901, SGC7901/DDP, HGC27, MGC803, BGC803, and BGC 823 gastric cancer cell lines. Inhibition of the STAT3 pathway after luteolin administration was mediated by the disruption of HSP90-STAT3 binding, which promoted its interaction with SHP-1. The anti-cancer efficacy of luteolin was confirmed in SGC7901, SGC7901/DDP, and HGC27 murine xenograft models [127]. Furthermore, luteolin and its derivative apigenin had a synergistic effect against $\mathrm{H} 358$ murine xenografts and Lewis lung carcinoma in vivo. Luteolin and apigenin inhibited lung cancer cell growth, induced apoptosis, and reduced IFN- $\boldsymbol{\gamma}$-induced PD-L1 expression at inflammatory sites by suppressing STAT3 phosphorylation [128]. Due to its anti-inflammatory and antioxidant properties, apigenin also inhibited tumor promotion of HepG2 HCC through inhibited cell proliferation and induced apoptosis and autophagy via PI3K/AKT/mTOR pathway inhibition [129]. Moreover, apigenin inhibited the phosphorylation 
Table 1 Flavonoids targeting inflammatory pathways associated with cancer initiation

\begin{tabular}{|c|c|c|c|c|}
\hline Flavonoid & Study design & Mechanisms & Dosage of the tested flavonoid & References \\
\hline Baicalin & Female $\mathrm{C} 3 \mathrm{H} / \mathrm{HeN}$ mice & $\begin{array}{l}\text { Baicalin treatment inhibited ROS } \\
\text { production via the downregulation of } \\
\text { p47p pox , a key component of NADPH } \\
\text { oxidase. Furthermore, baicalin inhib- } \\
\text { ited inflammatory cascades through } \\
\text { TLR4 suppression }\end{array}$ & $4 \mathrm{mg}$ baicalin per mouse & [93] \\
\hline Baicalein & C57BL/6J ApcMin/+/J mouse model & $\begin{array}{l}\text { Baicalein reduced the number of tumors } \\
\text { in the small intestine }(P<0.01) \text { and } \\
\text { colon }(P<0.05) \text { in the baicalein-treated } \\
\text { group compared to the non-treated } \\
\text { group. Additionally, ELISA analysis } \\
\text { of small intestine and colon tissue } \\
\text { revealed the downregulation of pro- } \\
\text { inflammatory cytokines, including } \\
\text { IL-1 } \beta, \text { IL-2, IL-6, IL-10, GM-CSF, and } \\
\text { G-CSF }\end{array}$ & $30 \mathrm{mg} / \mathrm{kg} /$ day & [94] \\
\hline Rutin & Female ICR mice & $\begin{array}{l}\text { ELISA analyses revealed the downregu- } \\
\text { lation of IL- } 1 \beta \text { in the colonic mucosa. } \\
\text { Moreover, the mRNA levels of } I L-1 \beta \\
\text { and } I L-6 \text { were decreased after rutin } \\
\text { administration. Symptoms of DSS- } \\
\text { induced colitis were attenuated by rutin }\end{array}$ & $6 \mathrm{mg} /$ day, $0.6 \mathrm{mg} /$ day and $60 \mathrm{mg} /$ day & [98] \\
\hline Myricetin & Male BALB/c mice & 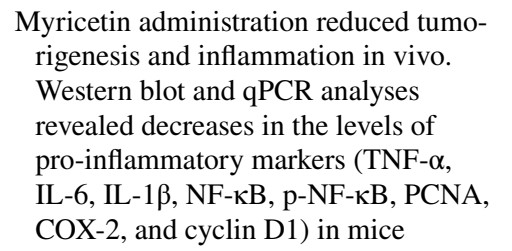 & $40 \mathrm{mg} / \mathrm{kg}$ and $100 \mathrm{mg} / \mathrm{kg}$ & [99] \\
\hline Naringin & Male C57BL/6 mice & $\begin{array}{l}\text { Oral administration of naringin pre- } \\
\text { vented colitis and carcinogenesis } \\
\text { induced by AOM/DSS through the } \\
\text { reduction of GM-CSF/M-CSF, IL-6, } \\
\text { and TNF and inhibition of the NF-kB/ } \\
\text { IL-6/STAT3 pathway }\end{array}$ & 50 and $100 \mathrm{mg} / \mathrm{kg}$ & {$[100]$} \\
\hline EGCG & Male BALB/c mice & $\begin{array}{l}\text { EGCG decreased oxidative stress } \\
\text { (increased SOD, CAT, and GSH activ- } \\
\text { ity, and decreased MDA and nitric } \\
\text { oxide). EGCG decreased the levels of } \\
\text { pro-inflammatory cytokines, including } \\
\text { IL-1 } \beta \text {, IL-6, and TNF- } \alpha\end{array}$ & $10 \mathrm{mg} / \mathrm{kg}$ & {$[103]$} \\
\hline GTPs & $\begin{array}{l}\text { Female } \mathrm{C} 3 \mathrm{H} / \mathrm{HeN} \text { mice, } \mathrm{IL}- \\
12 \mathrm{p} 40 \mathrm{KO} \text { mice on a } \mathrm{C} 3 \mathrm{H} / \mathrm{HeN} \\
\text { background }\end{array}$ & $\begin{array}{l}\text { GTPs inhibited UV-B-induced skin } \\
\text { carcinogenesis by downregulating pro- } \\
\text { inflammatory markers (COX-2, PGE2, } \\
\text { PCNA, TNF- } \alpha \text {, IL-6, and IL-1 } \beta \text { ) in } \\
\text { wild-type mice. GTP administration in } \\
\text { their counterparts, IL-12p40 knockout } \\
\text { mice, was less effective than in WT } \\
\text { mice. }\end{array}$ & Water containing GTPs $(0.2 \%, \mathrm{w} / \mathrm{v})$ & [104] \\
\hline Genistein & Sprague-Dawley rats & $\begin{array}{l}\text { Genistein inhibited Helicobacter } p .- \\
\text { induced gastropathy by suppressing } \\
\text { pro-inflammatory cytokine (TNF- } \alpha \text { and } \\
\text { CINC-1) production, NF- } \mathrm{KB} \text { activity, } \\
\text { and gastric cell apoptosis. }\end{array}$ & $16 \mathrm{mg} / \mathrm{kg}$ & [107] \\
\hline
\end{tabular}


Table 1 (continued)

\begin{tabular}{|c|c|c|c|c|}
\hline Flavonoid & Study design & Mechanisms & Dosage of the tested flavonoid & References \\
\hline Hesperidin & Male Swiss and LysM-eGFP mice & $\begin{array}{l}\text { Hesperidin demonstrated anti-inflam- } \\
\text { matory effects by inhibiting ROS } \\
\text { generation and IL-33, IL-1 } \beta \text {, IL-6, and } \\
\text { TNF- } \alpha \text { cytokine production through } \\
\text { the inhibition of NF- } \kappa \text { B. In addition, } \\
\text { hesperidin attenuated colitis symptoms, } \\
\text { including bowel edema, colon shorten- } \\
\text { ing, and macroscopic lesions. }\end{array}$ & 10,30 , or $100 \mathrm{mg} / \mathrm{kg}$ in saline & [110] \\
\hline Quercetin & Female Wistar rats & $\begin{array}{l}\text { Administration with Quecetrin (1mg/ } \\
\mathrm{kg} / \text { day) suppressed IL- } 1 \beta \text {, TNF- } \alpha \text {, and } \\
\text { iNOS expression through the inhibition } \\
\text { of the NF- } \mathrm{KB} \text { pathway in a rat model of } \\
\text { dextran sulfate sodium-induced colitis. }\end{array}$ & $1 \mathrm{mg} / \mathrm{kg} /$ day & [111] \\
\hline Luteolin & $\begin{array}{l}\text { BEAS- } 2 \mathrm{~B} \text { cells; }[\mathrm{Cr}(\mathrm{VI})] \text {-induced } \\
\text { BEAS- } 2 \mathrm{~B} \text { cells injected into mice }\end{array}$ & $\begin{array}{l}\text { Luteolin treatment suppressed the } \\
\text { promoter activity of AP-1, HIF-1 } \alpha \text {, } \\
\text { COX-2, and iNOS and the production } \\
\text { of IL-1 } \beta, \text { IL-6, IL- } 8 \text {, and TNF- } \alpha \text { in } \\
\text { BEAS-2B cells. Western blot analysis } \\
\text { revealed decreases in MAPK, NF- } \kappa B \text {, } \\
\text { COX-2, STAT-3, iNOS, and TNF- } \alpha \\
\text { protein levels in vitro. Reduction of } \\
\text { tumor frequency in mice injected with } \\
\text { [Cr(VI)]-exposed BEAS-2B cells }\end{array}$ & 1 and $2 \mu \mathrm{M}$ & [116] \\
\hline Apigenin & $16 \mathrm{HBE}$ and A549 cells & $\begin{array}{l}\text { Apigenin reduced miR- } 21 \text { and IL- } 8 \\
\text { mRNA expression in normal and can- } \\
\text { cerous cells exposed to CSE }\end{array}$ & $20 \mu \mathrm{M}$ & [117] \\
\hline
\end{tabular}

of the signaling molecules Lyn, Syk, phospholipase $\mathrm{C} \gamma 1$, ERK, and JNK and the expression of the cytokines TNF- $\alpha$, IL-4, IL-5, IL-6, IL-13, and COX-2-all of which induce inflammation and promote carcinogenesis-in RBL-2H3 rat leukemia cells [130]. Another study indicated that apigenin inhibited IL-6 expression and cell proliferation and promoted apoptosis by activating PARP and caspase- 8 in Eca-109 and Kyse-30 human esophageal cancer cells [131].

\section{Plant extracts rich in flavonoids}

Beyond isolated flavonoids, various plant extracts and flavonoids in whole plant foods exert beneficial effects against inflammation and associated tumor promotion. Co-administration of bilberry extracts and enzymatically modified isoquercitrin suppressed the promotion of HCC in PBOpromoted rats. This combination inhibited proliferation by reducing Ki67 and microsomal ROS levels. Bilberry extracts and isoquercitrin decreased p-PTEN, p-AKT, and Smad4 signaling - the downregulation of which was also connected with the inhibition of inflammation in PBO-promoted cases $[132,133]$. Furthermore, Id1 is overexpressed in nonsmall-cell lung carcinoma and exerts pro-inflammatory and tumor-promoting effects. Scutellaria flavonoids, especially the three prominent representatives (baicalin, baicalein, and wogonin), inhibited Id 1 through the activation of Rap1-GTP binding and the dephosphorylation of AKT and
Src in A549 cells, H1299 non-small-cell lung carcinoma cells, and murine A549 xenografts [134]. In another study, baicalein and baicalin inhibited tumor promotion by downregulating PD-L1 and pro-inflammatory cytokine IFN- $\gamma$. These results were associated with STAT3 suppression in the SMMC-7721 and HepG2 human liver cancer cell lines [135]. Moreover, flavonoid-rich ethanol extracts of whole dried sugarcane reduced NF- $\mathrm{\kappa B}$ phosphorylation and IL-8 secretion in SW480 colon cancer cells [136].

\section{Clinical studies}

Only limited clinical studies are based on the consistent molecular mechanisms of flavonoids against inflammation in different tumor stages. A botanical drug called APG-157 containing multiple polyphenols suppressed tumor cells due to its antioxidant and anti-inflammatory properties, as demonstrated by reduced IL- $1 \beta$, IL- 6 , and IL- 8 concentrations in the salivary supernatant fluid of oral cancer patients [137]. Moreover, fisetin improved the inflammatory status of colorectal cancer patients by reducing IL- 8 and hs-CRP levels [138]. Furthermore, consumption of green tea reduced $\mathrm{NF}-\mathrm{kB}$-associated inflammation in the radical prostatectomy tissue of men compared with black tea and water controls, suggesting that GTPs play a beneficial role in prostate cancer prevention and treatment [139]. Despite the known antiinflammatory effects of soy in men with prostate cancer 
[140], in women with early-stage breast cancer with the potential of tumor promotion and progression, soy supplements rich in genistein and daidzein led to the overexpression of cell cycle transcripts, including those that promote cell proliferation such as FGFR2, E2F5, BUB1, CCNB2, MYBL2, CDK1, and CDC20 [141].

Flavonoids can suppress tumor promotion of various cancer types through diverse anti-inflammatory mechanisms. Therefore, the evaluation of molecular and cellular mechanisms of tumor-promoting inflammation is essential for developing preventive and anti-cancer therapies in the preclinical and clinical spheres. Discussed anti-inflammatory effects of flavonoids against tumor promotion are summarized in Table 2. Moreover, Fig. 1 depicts the efficacy of flavonoids in tumor initiation and promotion, and the affected signaling molecules and pathways.

\section{Flavonoids as anti-inflammatory agents against tumor progression}

As discussed above, cancer progression is a complex process related to a broad spectrum of cellular and molecular signals; however, current research, especially preclinical in vitro and in vivo analyses, increasingly supports the efficacy of naturally occurring flavonoids against inflammation-associated migration, invasion, and metastasis, which are significant inducers of cancer progression [53, 55, 78, 142, 143].

\section{Preclinical research}

Biochanin $\mathrm{A}$, an O-methylated isoflavone, inhibited the release of pro-inflammatory cytokines TNF- $\alpha$ and IL- 6 from A427 lung cancer cells using the cocultured method. Moreover, biochanin A repressed the coculture-stimulated invasion of A427 cells accompanied by the modulation of EMT markers-downregulation of Snail and induction of E-cadherin. Indeed, due to the association between pro-inflammatory responses and tumor metastasis, the administration of biochanin A might alter the TME and thus hinder cancer migration and invasiveness [144]. Similarly, diosmetin isolated from Dracocephalum peregrinum L. repressed the migration and invasion of U251 glioma cells in vitro, as demonstrated by inhibition of the TGF- $\beta$ signaling pathway and upregulation of E-cadherin [143]. Also, hesperetin suppressed NF-кB activation and reduced the secretion of pro-inflammatory TNF- $\alpha$ and IL-6 in HepG 2 hepatic cancer cells; the antiinflammatory effects of hesperetin are attributed to reduced ROS overproduction by the Nrf2 pathway [145].

Furthermore, EGCG suppressed the invasion, migration, and metastasis of Panc- 1 and MIA PaCa- 2 pancreatic cancer cells by the inhibition of the AKT pathway and modulation of EMT markers, specifically upregulated E-cadherin and downregulated $\mathrm{N}$-cadherin and the mesenchymal markers TCF8/ZEB1, $\beta$-catenin, and vimentin [146]. Moreover, the novel synthetic flavonoid LFG-500 blocked the EMT and metastasis by downregulating YAP activity via ILK in MCF-7 breast cancer and A549 lung cancer cell models of TGF- $\beta$-induced EMT [76]. In addition, myricetin inhibited the invasion and migration of radioresistant A549-IR lung cancer cells, as demonstrated by the suppression of MMP-2 and MMP-9 (through FAK-ERK inhibition) and the EMT marker Slug [147]. Similarly, myricetin treatment potently inhibited the cytokine-induced migration and invasion of KKU-100 cholangiocarcinoma cells, mediated partially through STAT3 suppression; myricetin also suppressed downstream target genes of STAT3, including ICAM-1, MMP-9, iNOS, and COX-2 [148]. In addition, the newly synthesized flavonoid derivative GL-V9 suppressed the invasion and migration of HCT116 and SW480 colorectal cancer cells by inhibiting PI3K/AKT and MMP-2/9 signaling [149]. Moreover, baicalein showed anti-metastatic activity in breast cancer in vitro and in vivo demonstrated by the inhibition of STAT3 activity and suppressed IL-6 [150]. Also, chrysin and daidzein decreased CXCL1 and MMP-9, essential molecules released by the TME that facilitate tumor progression in the rat model of colorectal cancer; therefore, chrysin and daidzein have potential in preventing colorectal cancer angiogenesis and metastasis [151].

Moreover, chrysin inhibited the pro-inflammatory cytokine-induced EMT phenotype and CSC-like characteristics in HeLa cervical cancer cells by blocking the NF- $\mathrm{KB}$ / Twist axis [142]. Also, the citrus peel-derived flavonoid tangeretin inhibited breast CSC formation by suppressing STAT3 and reducing Sox2 levels [152]. In addition, the capacity of 8-bromo-7-methoxychrysin to reverse the M2 polarization of TAMs by inhibiting NF- $\mathrm{NB}$ highlights its potential to disrupt interactions between LCSLC and TAMs; indeed, M2 polarization of TAMs in the TME promotes the LCSLC capability of self-renewal [153].

Due to the association between inflammation and angiogenesis in tumor cells, Gong et al. (2018) evaluated the effects of flavonoids in the extract of Scutellariae Radix on inflammation-induced angiogenic responses. Eventually, Scutellariae Radix extract at various concentrations (0.03, $0.1,0.3,1.0 \mathrm{mg} / \mathrm{mL}$ ) applied for $48 \mathrm{~h}$ decreased pro-inflammatory cytokines IL- $1 \beta$, IL- 6 , and TNF- $\alpha$, and suppressed the expression of the angiogenic biomarkers NF- $\kappa \mathrm{B}, \mathrm{Cox}-2$, iNOS, and VEGF in LPS pre-treated cultured macrophage RAW 264.7 cells [154]. In addition, luteolin showed a potent capacity to target HIF-1 $\alpha /$ VEGF signaling-mediated EMT and angiogenesis, as demonstrated by EMT suppression (increased E-cadherin and decreased $\mathrm{N}$-cadherin and vimentin) and the downregulation of p-AKT, HIF-1 $\alpha$, VEGF-A, p-VEGFR-2, MMP-2, and MMP-9 in A375 and B16-F10 melanoma cells [155]. Moreover, EGCG and silibinin 


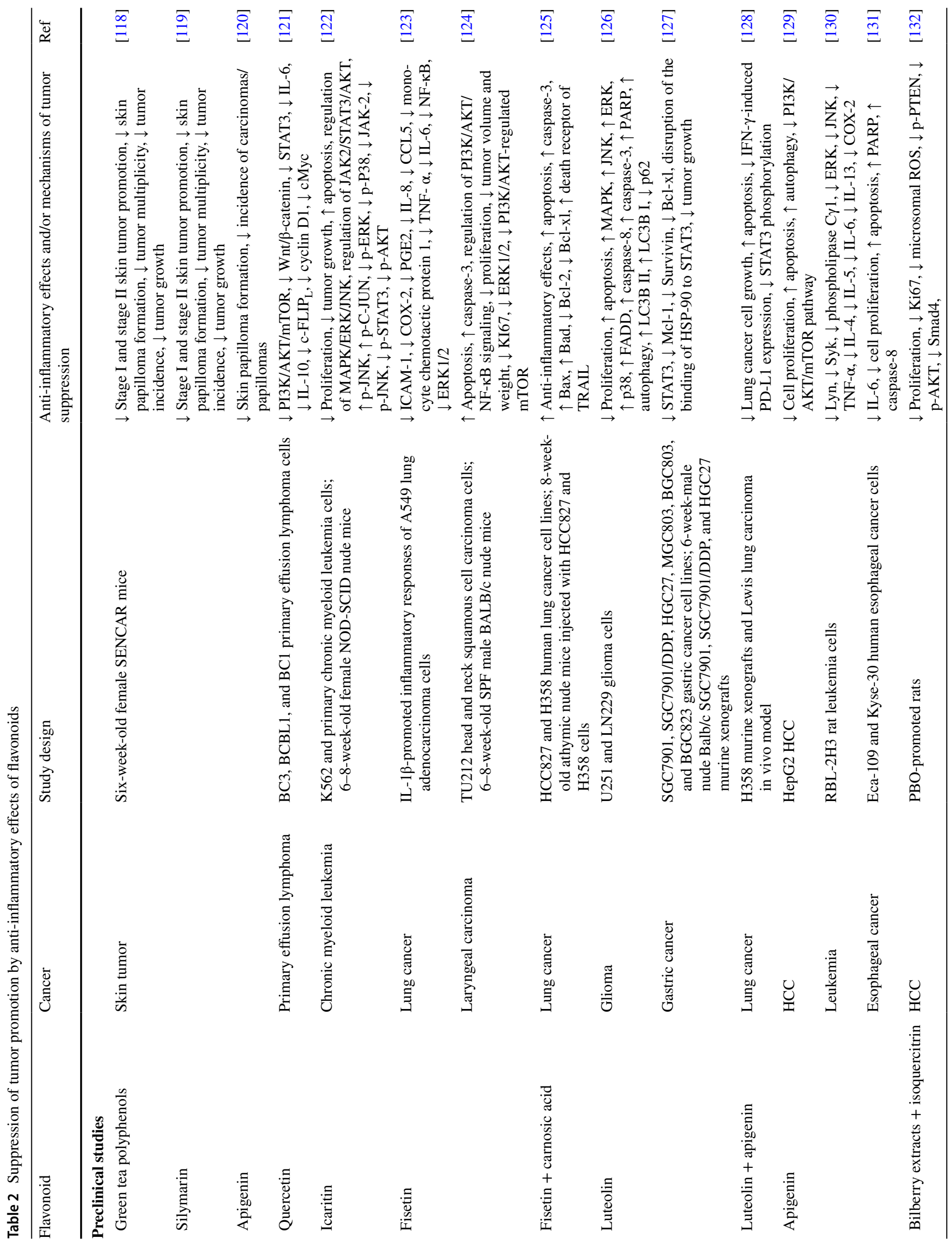




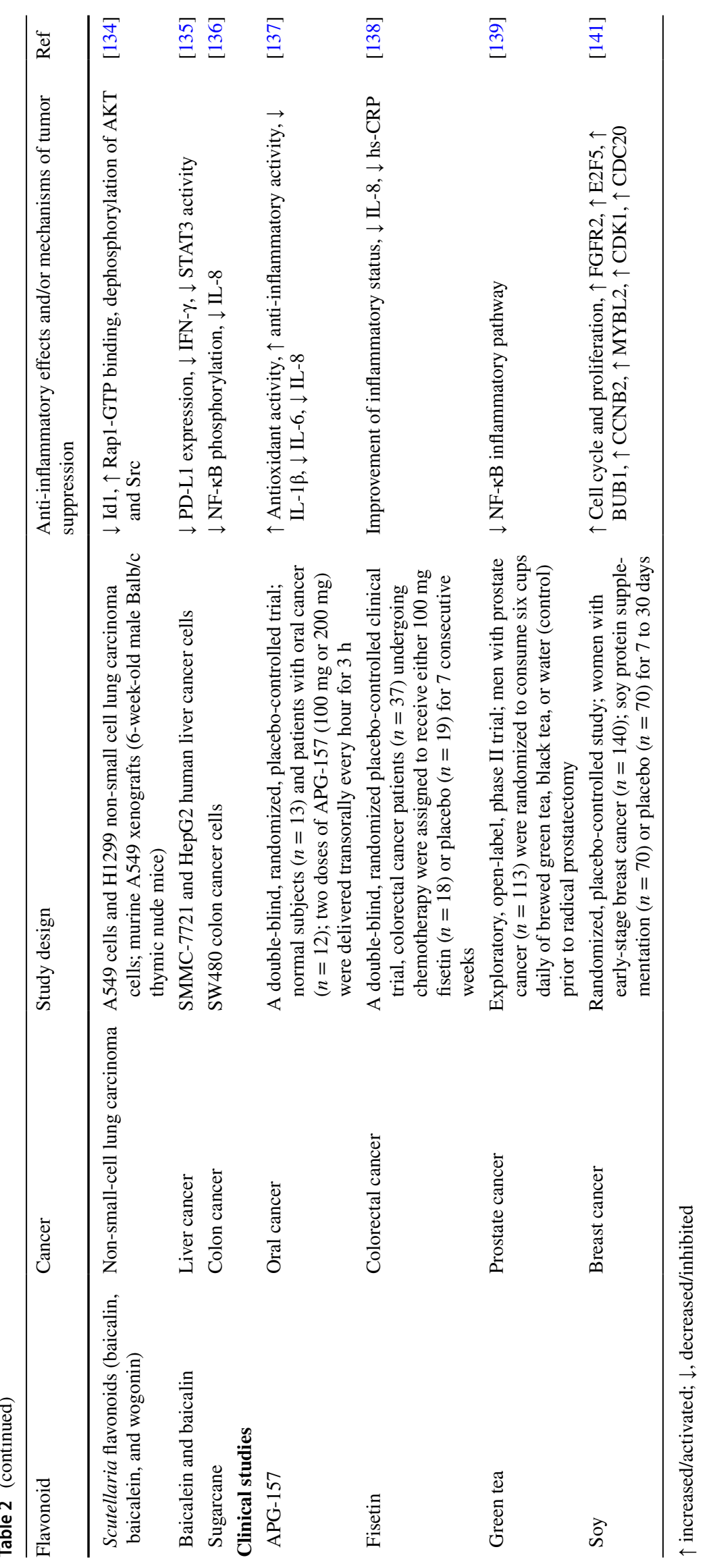


Fig. 1 Suppression of tumor initiation and promotion by flavonoids. Abbreviations: $\uparrow$ increased/activated; $\downarrow$ decreased/inhibited

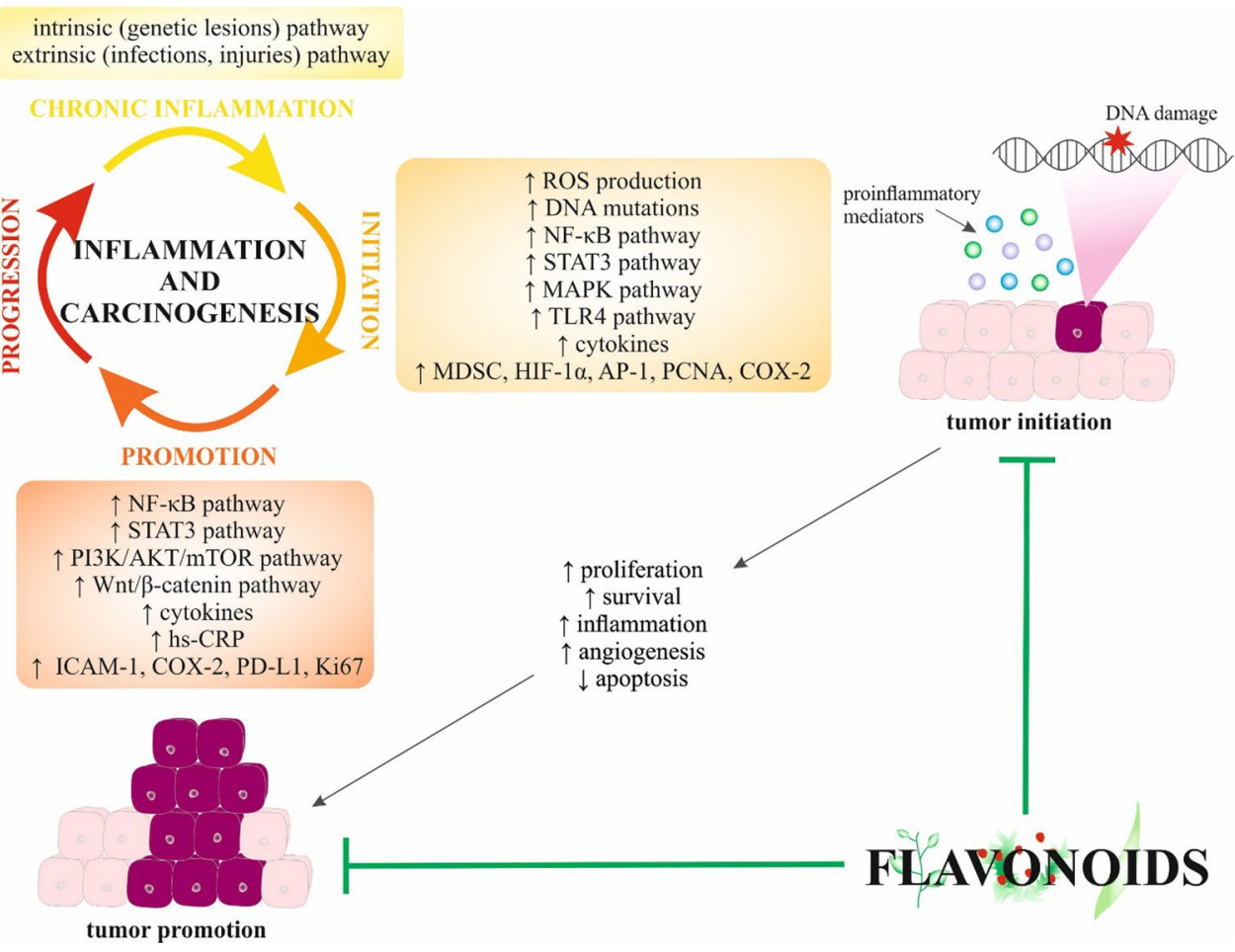

suppressed the migration of endothelial and lung tumor cells and downregulated VEGF, VEGFR2, and pro-angiogenic members of the miR-17-92 cluster [156].

Also, WCE rich in flavonoids suppressed IL-6, CXCL1, and CXCL8 thus reducing tumor-elicited infiltration MDSCs, TAMs, and endothelial cells accompanied by reduced STAT3 activation, in MDSCs in PC-3 and DU145 prostate cancer xenografts. At the same time, these effects resulted in the inhibition of angiogenesis and metastasis [157]. Furthermore, EGCG attenuated immunosuppression in a 4T1 murine model of breast cancer by decreasing the accumulation of MDSCs and increasing $\mathrm{CD}^{+}$and $\mathrm{CD}^{+} \mathrm{T}$ cell numbers, suggesting that EGCG could effectively enhance the anti-tumor response [78]. Also, limonin decreased inflammation by reducing TNF- $\alpha$ and enhanced the adaptive immune response by promoting the immunophenotyping of CD8, CD4, and CD19 lymphocytes in a $\mathrm{Balb} / \mathrm{c}$ murine model of colorectal carcinogenesis; limonin thus demonstrated immune-stimulating effects [158]. Figure 2 depicts the anti-inflammatory effects of naturally occurring flavonoids targeting the progression of cancer.

In conclusion, the results of current preclinical research highlight the effectiveness of flavonoids against inflammation-associated cancer progression (Table 3).

\section{Clinical studies}

The above-discussed results of preclinical investigations support the need for further clinical evaluation of flavonoids to target the inflammation-induced progression of cancer. Indeed, Polyphenon E, which contains mainly EGCG and epicatechin, epigallocatechin, and epicatechin3-gallate in lesser amounts, significantly reduced VEGF and HGF levels in a study of 26 men with positive prostate biopsies scheduled for radical prostatectomy [159]. Moreover, a randomized, phase II trial (conducted on 32 patients with prostate cancer) revealed that consuming bread enriched in soy isoflavones is associated with reduced pro-inflammatory cytokine levels and reduced ratios of $\mathrm{T}$ regulatory cells to $\mathrm{CD} 8+$ cells and MDSCs in peripheral blood. These results support the potential efficacy of flavonoids in promoting immune surveillance during cancer progression [140]. In addition, the positive effects of lifestyle modifications, including physical activity and diets rich in fruits and vegetables, were demonstrated by a clinical trial that revealed decreased TNF- $\alpha$ levels in BRCA1/2+ breast cancer survivors following a yearlong lifestyle modification program [160].

In conclusion, pre-clinical and clinical investigations point to the potential of flavonoids modulating all stages of the complex process of carcinogenesis associated with inflammation. Obtaining data to enable the implementation of agents precisely targeting specific stages of carcinogenesis will allow the utilization of predictive, preventive, and personalized approaches that increase efficiency and decrease cancer management costs. 


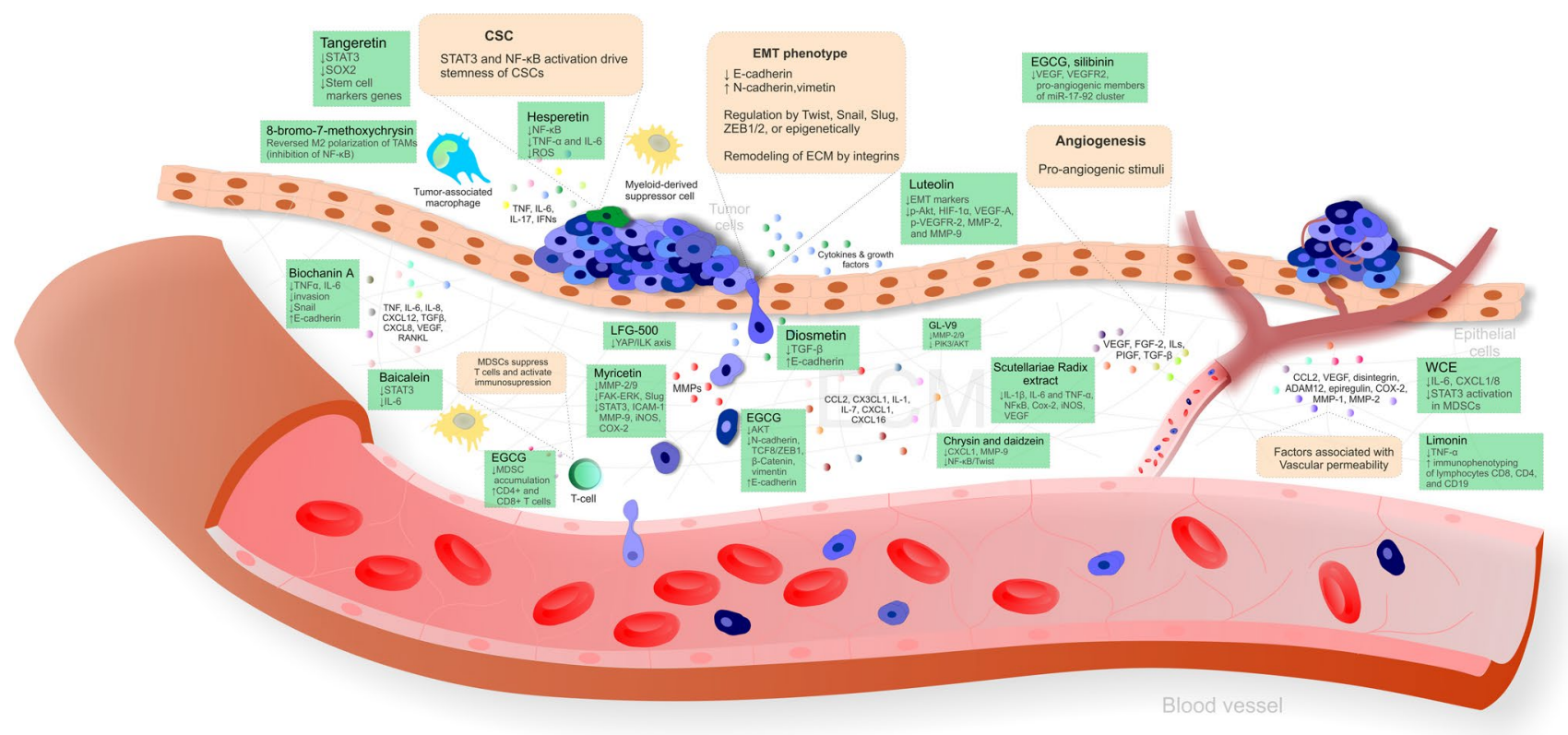

Fig. 2 The effectiveness of flavonoids as anti-inflammatory agents against tumor progression. Abbreviations: $\uparrow$ increased/activated; $\downarrow$ decreased/ inhibited

\section{Exemplified 3PM pathways}

As detailed above, non-physiologic inflammation may initiate carcinogenesis and evidently contribute to tumor development and progression as well as it deteriorates individual outcomes in the cohort of cancer patients [161]. The good news is that, due to their evident anti-inflammatory properties, flavonoids are clinically relevant candidates as preventive and therapeutic agents to improve individual outcomes in diseases linked to the non-physiologic inflammation. The challenge is, however, to diagnose well in time an individual predisposition to non-physiologic inflammatory processes such as low-grade chronic inflammation that is definitely the task for predictive diagnostics tools and targeted individualized prevention. Clinical translation is a process of application of preclinical observations and results after clinical validation into medical practice. All described flavonoids targeting specific signaling cascades associated with inflammation are components of different plants, and their synergic/additive effects are associated with supporting human health. The implication of $3 \mathrm{PM}$ as a concept of medicine of the twenty-first century into routine clinical practice is, among other things, based on increasing the amount of flavonoid intake from food due to their beneficial aspect in the prevention of various pathologies. Table 4 links the previously referred preclinical research on some flavonoids to the practical amount of particular food in the daily diet.

To this end, individualized profiling based on specialized survey and specific multi-diagnostic patterns has been demonstrated as instrumental for primary, secondary, and tertiary healthcare exemplified below.

A. Primary healthcare: prediction of relevant suboptimal health conditions such as family (genetic) predisposition, abnormal BMI (both overweight and underweight), abnormal stress reactions, disturbed microcirculation, and delayed healing, among others [171-175]; based on anti-inflammatory properties of flavonoids, corresponding individualized mitigating measures may be considered as follows. Healthy and balanced diet rich in naturally occurring phytochemicals including flavonoids is essential to prevent non-communicable diseases associated with non-physiologic inflammation [55, 176, 177]. In particular, flavonoids show significant efficacy to maintain optimal weight, including less likeliness to be obese $[176,178,179]$. Preclinical research elaborate the effectiveness of flavonoids to prevent inflammation associated with obesity [180, 181]; moreover, these results are supported by clinical studies conducted on specific parts of the population evaluating individual health conditions. Indeed, a randomized clinical trial by Lee et al. (2016) demonstrated the efficacy of anthocyanin-rich black soybeans to reduce abdominal fat and lipid profiles in overweight or obese paticipants [182]. Moreover, anthocyanin exerted beneficial metabolic effects demonstrated through the prevention of insuline resistance in subjects with type 2 diabetes [183]; besides, current evidence highlights the association between cancer and insulin resistance, which is common in obese individuals 


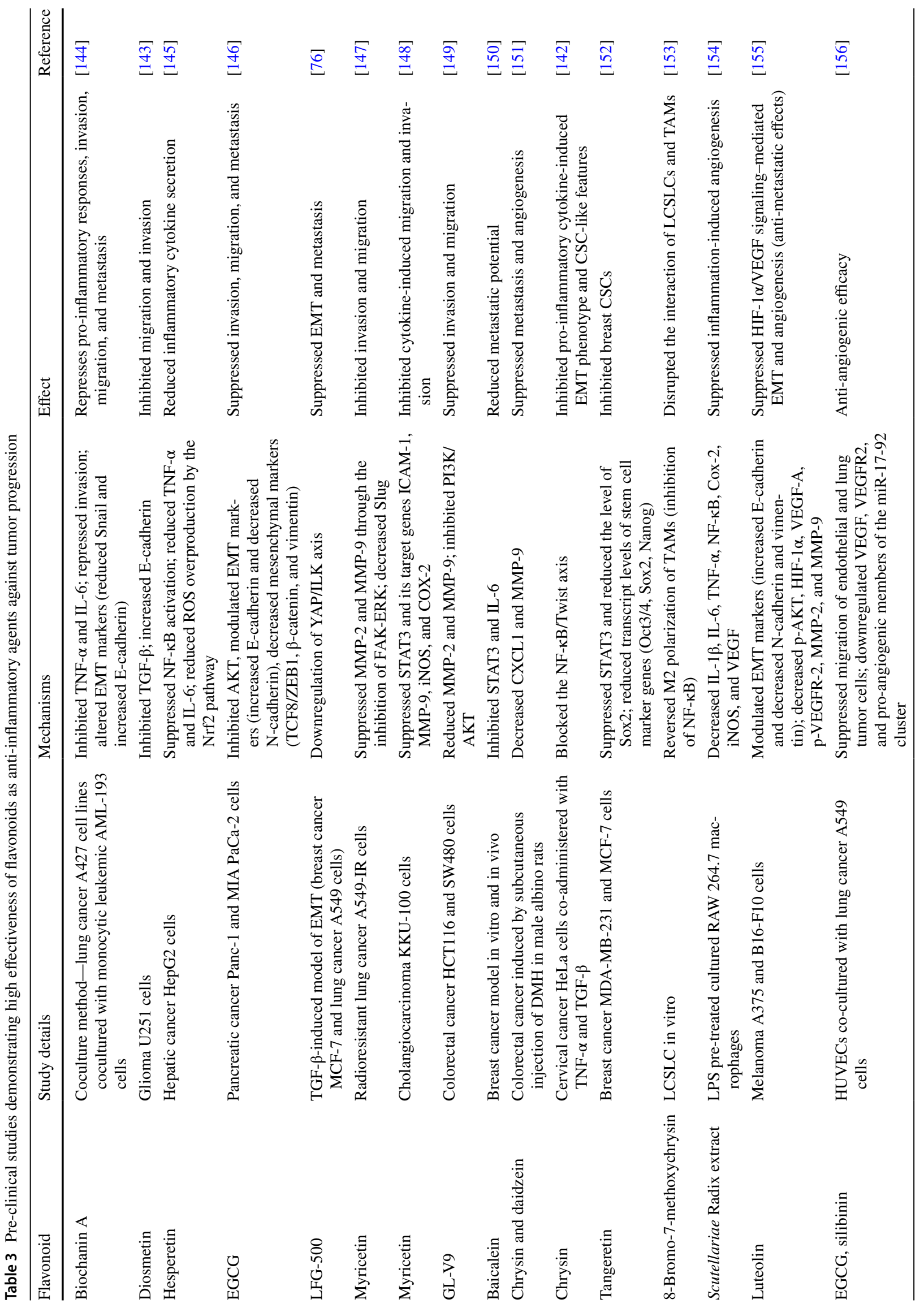


and type 2 diabetes [184]. Also, flavonoids are efficient agents mitigating chronic stress and improving overall brain health $[185,186]$. Cocoa products were found to induce anti-inflammatory effects demonstrated through decreased IL-10 and IL-1 $\beta$ in healthy and hypercholesterolaeic individuals [187]. Similarly, results of a double-blinded randomized trial showed the association of high-polyphenol chocolate and increased ICAM-1 in type 2 diabetes when compared with control [188]. The potent capacity of flavonoids in the primary healthcare mediated through multiple mechanisms of action including the anti-inflammatory capacity is demonstrated also by the maintenance of cardiovascular health $[189,190]$ or wound healing [191, 192]. Clinical evidence demonstrate honey, a rich source of flavonoids [193], to exert efficacy during healing of wounds and ulcers that had failed to heal using conventional approaches [194]; thus, honey possesses the ability to resolve the inflammatory state of chronic wounds [195]. Also, clinical and epidemiological data support the notion of effectiveness of flavonoids to prevent conditions associated with increased risk of malignant diseases [89, 196-198]. Indeed, soy isoflavone was found to increase serum IL-6 in postmenopausal women and thus enhancing the immune surveillance associated with lower incidence of cancer in parts of the world characterized by higher soy intake [199]. Furthermore, mediterranean diet exerted potential beneficiary effects in primary breast cancer prevention [200] preventing all breast cancer subtypes [201], presumably through various anti-cancer mechanisms including anti-inflammatory activity. Therefore, due to their anti-inflammatory capacity, naturally occurring flavonoids and flavonoid-rich plant food represent potent agents for primary healthcare of suboptimal health conditions and/or specific disease predisposition associated with the risk of cancer .

B. Secondary healthcare: prediction of tumor progression and increased risk of pre-metastatic niches/metastatic disease [4, 202, 203]; as mentioned above, flavonoids were comprehensively documented to prevent the onset of the cancer invasiveness in preclinical research via the modulation of numerous signaling pathways involved in critical steps of metastatic spread. In addition, flavonoids were described to be effective oncostatic substances in highly aggressive cancer models including various in vivo approaches. Regarding oncology practice, flavonoids demonstrated promising results applied in the combination with conventional chemotherapeutics in metastatic cancer disease. However, in-depth analyses of re-sensitizing cancer cells by flavonoids towards conventional chemotherapy and assessing the activities of flavonoids on cancer stem cells survival, affecting the relapse and multidrug resistance, are needed [55]. 
Table 4 Content of flavonoids in foods

\begin{tabular}{|c|c|c|c|}
\hline Flavonoids & Food source & $\begin{array}{l}\text { Amounts of flavonoids in } \\
\text { food } \mathrm{mg} / 100 \mathrm{~g}\end{array}$ & References \\
\hline \multirow[t]{5}{*}{ (-)-Epicatechin } & Apples (raw, with skin) & 15.12 & {$[162]$} \\
\hline & Peaches (raw) & 12.24 & {$[162]$} \\
\hline & Cranberries (raw) & 25.93 & {$[162]$} \\
\hline & Cocoa (dry powder) & 183.49 & {$[162]$} \\
\hline & Red wine (table) & 20.49 & {$[162]$} \\
\hline \multirow[t]{3}{*}{ Myricetin } & Blueberries & 1.26 & {$[162]$} \\
\hline & Garlic & 1.61 & {$[162]$} \\
\hline & Red wine & 0.83 & [163] \\
\hline Biochanin A & Peanut & 0.06 & {$[164]$} \\
\hline Baicalein & Welsh onion & $1.80 \mathrm{e}-03$ & {$[165]$} \\
\hline \multirow[t]{2}{*}{ Quercetin-3-O-glucoside } & Onions & 21.40 & {$[162]$} \\
\hline & Kale & 22.58 & {$[162]$} \\
\hline Daidzein & Tempeh & 22.66 & [166] \\
\hline \multirow[t]{2}{*}{ Tangeretin } & Orange juice & 0.3 & {$[167]$} \\
\hline & Soybean & 61.33 & [166] \\
\hline \multirow[t]{3}{*}{ Genistein } & Tofu & 12.99 & [166] \\
\hline & Tempeh & 36.15 & [166] \\
\hline & Soy milk & 4.94 & [168] \\
\hline \multirow[t]{2}{*}{ Diosmetin 7-O-rutinoside } & Lemon—pure juice & 2.92 & [169] \\
\hline & Peppermint & 95.50 & [169] \\
\hline \multirow[t]{2}{*}{ Hesperetin } & Lemon juice & 14.47 & {$[162]$} \\
\hline & Orange juice & 20.39 & {$[162]$} \\
\hline \multirow[t]{2}{*}{ Apigenin } & Spices, celery seed & 83.70 & [162] \\
\hline & Peppermint & 8.71 & [162] \\
\hline \multirow[t]{3}{*}{ Luteolin } & Green peppers & 4.71 & [162] \\
\hline & Olive oil & 0.36 & {$[170]$} \\
\hline & Pistachio & 0.10 & {$[170]$} \\
\hline
\end{tabular}

There are only limited clinical data evaluating the effectiveness of flavonoids against advanced cancer disease. Curcumin has been documented to suppress cancer cells due to its anti-inflammatory and antioxidant effects. On the other hand, its effectiveness is limited by poor absorption after oral administration. A botanical drug APG-157 containing multiple polyphenols, including flavonoids, demonstrated improved bioavailability and clinical activity in patients with oral cancer. APG-157 was well absorbed, reduced parameters of inflammation, and upregulated expression of genes linked with differentiation and $\mathrm{T}$ cell recruitment to the TME. These data shows the potential using of APG-157 in combination with anti-cancer therapies including advanced disease [137]. In another clinical study, fisetin reduced the plasma levels of IL-8, hs-CRP, and MMP-7 levels $(p<0.02)$ [138]. Green tea and its constituents, mainly EGCG, show anti-inflammatory activities associated with reduced VEGF and HGF levels in prostate cancer patients $[139,159]$. Oral administration of soy isoflavone-enriched bread significantly suppressed proinflam- matory cytokines and immunosuppressive cells in men with prostate cancer [140]. Finally, lifestyle modifications in BRCA $1 / 2+$ breast cancer survivors, including physical activity and diets rich in flavonoids (in fruits and vegetables), revealed decreased TNF- $\alpha$ levels [160]. All these mentioned clinical data suggest antimetastatic potential of fisetin, green tea, soy, and fruit and vegetrables rich in flavonoids in cancer patients. Based on preclinical research, there are numerous studies demonstrating high effectiveness of flavonoids and flavonoid-rich extracts as anti-inflammatory agents against tumor progression. These include biochanin A, diosmetin, hesperetin, EGCG, synthetic flavonoids LFG500 and GL-V9, myricetin, baicalein, chrysin, daidzein, tangeretin, 8-bromo-7-methoxychrysin, Scutellariae Radix extract, luteolin, silibinin, WCE, and limonin (see Table 3).

C. Tertiary healthcare: prediction in palliative care [204]; in this regard, flavonoids were described to block an activation of numerous cellular regulatory proteins such as cytokines and transcription factors involved in cel- 
lular inflammatory responses and pain. From the clinical point of view, it could be very beneficial to develop protective delivery formulations containing flavonoids to treat inflammation and pain. Flavonoids suppress the expression of wide spectrum of inflammatory molecules such as NO, TNF- $\alpha$, IL-1 $\beta$, and COX-2; downregulate ICAM-1 and VEGF synthesis; and, moreover, activate STAT3, NF-kB, NLRP3 inflammasome, and finally MAPK cellular pathways. Based on mentioned multitarget activities of flavonoids, they have great potential in clinical sphere, including oncology practice, due to their anti-inflammatory and analgesic properties [205].

There are several examples of specific flavonoids that should be beneficial in palliative care in cancer patients. In the case report, the breast cancer patient showed progressive liver failure despite several chemotherapy treatments, including paclitaxel, capecitabine, and vinorelbine. Silibinin application improved hepatic failure due to extensive liver infiltration in this patient. After the initiation of therapy, the patient showed clinical and liver improvements that permitted the continuation of palliative chemotherapy [206]. Harati et al. (2017) documented that EGCG and silibinin represent potential candidate molecules as mild therapeutic options for patients with solid sarcomas that require palliative treatment and are not suitable for doxorubicin-based chemotherapy [207]. In another preclinical study, baicalelin and 6-gingerol reduced 5-fluorouracil-induced overexpression of CXCL1 in the colon and prevented the development of neutrophil recruitment and weakened diarrhea development by the suppression of NF- $\kappa$ B activity [208]. Data from another preclinical study point out to protective role of quercetin coadministered with vitamin $\mathrm{E}$ in the prevention of doxorubicin-induced toxicity in uterine and ovarian tissues in rats [209]. The administration of casticin in male rats demonstrated a palliative effects against cisplatin-induced renal damage and recovered all renal parameters to normal levels [210].

Besides cancer, there are also other life-threatening disease/condition in which flavonoids show positive palliative effects. Using mouse model, EGCG significantly reduced osteoarthritis disease progression and exerts palliative effects [211]. Kaswan et al. (2021) described that the serotonergic pathway (via the 5-HT1A receptor subtype in the central nervous system) is essential for cardamonin to suppress neuropathic pain in chronic constriction injury-induced neuropathic pain animal model [212]. EGCG administration modulating the $\mathrm{Wnt} / \beta$-catenin signaling pathways reduced postoperative pain related to inflammatory and neurochemical alterations [213]. Most of the above data are from preclinical research; therefore, well-controlled clinical studies are needed to validate the positive effects of flavonoids in palliative care in patients with cancer as well as other diseases.

\section{Strengths and limitations}

Phytochemicals represent naturally occuring anti-cancer agents affecting numerous cellular pathways. However, the utilization of flavonoids in clinical practice to prevent or treat cancer still faces difficulties associated with limitations of studies performed. The efficacy of flavonoids as anti-inflammatory agents in vivo is strongly dependent on its bioavailability affected by various factors on the side of the individual recipient or properties of the flavonoid itself including low absorption, an extensive metabolization, rapid elimination, or structural complexity of flavonoids within subclasses [55]. For example, catechins appear to be absorbed in amount smaller than intake due to their rapid metabolization [214]. Therefore, an increase in the bioavailablity of flavonoids envisaged by current research [215]. To this end, complexity and chronicity as basic characteristcs of plenty of human diseases as well as sex, age, comorbidities, genetic similarity, and environmental factors should be carefully considered and appropriately modeled in research and individualised application of flavonoids [216].

The abovementioned limitations associated with the evaluation of anti-cancer effects of phytochemicals in vitro and in vivo are, further, exemplified below. Preclinical in vitro studies demonstrate potent capacity of soy isoflavones to suppress prostate carcinogenesis [217]. However, as stated by Miltyk et al. (2003), despite the capacity of isoflavone to induce genetic damage of prostate cancer cells in vitro, similar effects were not observed in human subjects [218]. Similarly, isoflavones exerted no effects on markers of inflammation [219] and had no effect on prostate-specific antigen or hormone levels in prostate cancer patients [220]. However, the evaluation of other doses and duration of the administration in further research of anti-cancer efficacy of isoflavones in prostate cancer might be beneficial for the data interpretation [219].

The preventive efficacy of EGCG was supported by the detection of methylated and nonmethylated forms of EGCG in prostate tissue after short-term green tea intervention [221]. Further, potent capacity of a mixture of natural agents to protect human lymphocytes in vitro in comparison with single agents [222] was further emphasized by a proof-ofconcept study in humans in vivo [223]. Phytochemicals, for example tannins, chelate metal ions that generate ROS and thus stabilize potential pro-oxidant activity [224]. , In conclusion, to overcome persisting limitations in the field, intensified preclinical [225] and clinical research [159, 225] on phytochemicals is essential to be performed in 
the framework of predictive, preventive and personalized medicine.

Supplementary Information The online version contains supplementary material available at https://doi.org/10.1007/s13167-021-00257-y.

Code availability Not applicable.

Author contribution P. K. and O. G. were responsible for the paper conception and final data interpretation and presentation. The manuscript was drafted by P. K., A. L., L. K., M. S. (Marek Samec), K. K., and D. V. and critically revised by P. K., K. B., K. Z., A. B., R. I., F. A. G., and O. G. Figures were prepared by M. S. (Marek Samec), L. K., and A. L. P. K., O. G., M. S. (Mehdi Shakibaei), and D. B. provided skilled assistance and supervised the overall preparation of the manuscript. All authors have read and agreed to the published version of the manuscript.

Funding Open Access funding enabled and organized by Projekt DEAL. The present study was supported by the Scientific Grant Agency of the Ministry of Education, Science, Research and Sport of the Slovak Republic (Bratislava, Slovak Republic; grant no. VEGA 1/0136/19); the Slovak Research and Development Agency under Contract No. APVV16-0021; and the LISPER project (grant Nr. 313011V446) in bilateral agreement with the European Association for Predictive, Preventive, and Personalised Medicine. D. B. was supported by a National Priorities Research Program grant (NPRP 11S-1214-170101) from the Qatar National Research Fund (QNRF, a member of Qatar Foundation).

Data availability Not applicable.

\section{Declarations}

Ethics approval Not applicable.

Consent to participate Not applicable.

Consent for publication Not applicable.

Conflict of interest The authors declare no competing interests.

Open Access This article is licensed under a Creative Commons Attribution 4.0 International License, which permits use, sharing, adaptation, distribution and reproduction in any medium or format, as long as you give appropriate credit to the original author(s) and the source, provide a link to the Creative Commons licence, and indicate if changes were made. The images or other third party material in this article are included in the article's Creative Commons licence, unless indicated otherwise in a credit line to the material. If material is not included in the article's Creative Commons licence and your intended use is not permitted by statutory regulation or exceeds the permitted use, you will need to obtain permission directly from the copyright holder. To view a copy of this licence, visit http://creativecommons.org/licenses/by/4.0/.

\section{References}

1. De Pasquale C, Campana S, Bonaccorsi I, Carrega P, Ferlazzo G. ILC in Chronic Inflammation, cancer and targeting with biologicals. Mol Aspects Med. 2021;80:100963. https://doi.org/10. 1016/j.mam.2021.100963.
2. Awad RM, De Vlaeminck Y, Maebe J, Goyvaerts C, Breckpot K. Turn back the TIMe: targeting tumor infiltrating myeloid cells to revert cancer progression. Front Immunol. 1977; 2018:9. https:// doi.org/10.3389/fimmu.2018.01977.

3. Koklesova L, Liskova A, Samec M, Qaradakhi T, Zulli A, Sme$\mathrm{jkal} \mathrm{K}$, et al. Genoprotective activities of plant natural substances in cancer and chemopreventive strategies in the context of $3 \mathrm{P}$ medicine. EPMA J. 2020;11:261-87. https://doi.org/10.1007/ s13167-020-00210-5.

4. Crigna AT, Samec M, Koklesova L, Liskova A, Giordano FA, Kubatka P, et al. Cell-free nucleic acid patterns in disease prediction and monitoring-hype or hope? EPMA J. 2020:1-25. https:// doi.org/10.1007/s13167-020-00226-x.

5. Shimizu K, Iyoda T, Okada M, Yamasaki S, Fujii S. Immune suppression and reversal of the suppressive tumor microenvironment. Int Immunol. 2018;30:445-55. https://doi.org/10.1093/ intimm/dxy042.

6. Rossi J-F, Lu ZY, Massart C, Levon K. Dynamic immune/inflammation precision medicine: the good and the bad inflammation in infection and cancer. Front Immunol. 2021;12:595722. https:// doi.org/10.3389/fimmu.2021.595722.

7. Hussain SP, Harris CC. Inflammation and cancer: an ancient link with novel potentials. Int J Cancer. 2007;121:2373-80. https:// doi.org/10.1002/ijc.23173.

8. Greten FR, Grivennikov SI. Inflammation and cancer: triggers, mechanisms, and consequences. Immunity. 2019;51:27-41. https://doi.org/10.1016/j.immuni.2019.06.025.

9. Gupta SC, Kunnumakkara AB, Aggarwal S, Aggarwal BB. Inflammation, a double-edge sword for cancer and other agerelated diseases. Front Immunol. 2018;9:2160. https://doi.org/ 10.3389/fimmu.2018.02160.

10. Petts D, Wren M, Nation B, Guthrie G, Kyle B, Peters L, et al. A short history of occupational disease: 2. Asbestos, chemicals, radium and beyond. Ulster Med J. 2021;90:32-4.

11. Stone TW, McPherson M, Gail Darlington L. Obesity and cancer: existing and new hypotheses for a causal connection. EBioMed. 2018;30:14-28. https://doi.org/10.1016/j.ebiom.2018.02.022.

12. Bousquenaud M, Fico F, Solinas G, Rüegg C, Santamaria-Martínez A. Obesity promotes the expansion of metastasis-initiating cells in breast cancer. Breast Cancer Res. 2018;20:104. https:// doi.org/10.1186/s13058-018-1029-4.

13. Ding S, Jiang H, Fang J. Regulation of immune function by polyphenols. J Immunol Res. 2018;2018:e1264074. https://doi.org/ 10.1155/2018/1264074.

14. Yahfoufi N, Alsadi N, Jambi M, Matar C. The immunomodulatory and anti-inflammatory role of polyphenols. Nutrients. 2018;10, https://doi.org/10.3390/nu10111618.

15. Kopustinskiene DM, Jakstas V, Savickas A, Bernatoniene J. Flavonoids as anticancer agents. Nutrients. 2020;12, https://doi.org/ 10.3390/nu12020457.

16. Anuja K, Roy S, Ghosh C, Gupta P, Bhattacharjee S, Banerjee B. Prolonged inflammatory microenvironment is crucial for pro-neoplastic growth and genome instability: a detailed review. Inflamm Res. 2017;66:119-28. https://doi.org/10.1007/ s00011-016-0985-3.

17. Rozhok A, DeGregori J. A generalized theory of age-dependent carcinogenesis. eLife. 2019;8:e39950. https://doi.org/10.7554/ eLife.39950.

18. To EE, O'Leary JJ, O'Neill LAJ, Vlahos R, Bozinovski S, Porter $\mathrm{CJH}$, et al. Spatial properties of reactive oxygen species govern pathogen-specific immune system responses. Antioxid Redox Signal. 2020;32:982-92. https://doi.org/10.1089/ars.2020.8027.

19. Alena L; Marek S; Lenka K; Erik K; Peter K. Golubnitschaja olga mitochondriopathies as a clue to systemic disorders: "vicious circle" of mitochondrial injury, analytical tools and mitigating measures in context of predictive, preventive, and 
personalized (3P) medicine. 2021;22:2007, https://doi.org/10. 3390/ijms22042007.

20. Aceto GM, Catalano T, Curia MC. Molecular aspects of colorectal adenomas: the interplay among microenvironment, oxidative stress, and predisposition. Biomed Res Int. 2020;2020:1726309. https://doi.org/10.1155/2020/1726309.

21. de Barrios O, Sanchez-Moral L, Cortés M, Ninfali C, ProfitósPelejà N, Martínez-Campanario MC, et al. ZEB1 promotes inflammation and progression towards inflammation-driven carcinoma through repression of the DNA repair glycosylase MPG in epithelial cells. Gut. 2019;68:2129-41. https://doi.org/ 10.1136/gutjnl-2018-317294.

22. Gobert AP, Wilson KT. Polyamine- and NADPH-dependent generation of ROS during Helicobacter pylori infection: a blessing in disguise. Free Radic Biol Med. 2017;105:16-27. https://doi. org/10.1016/j.freeradbiomed.2016.09.024.

23. du Plessis M, Davis T, Loos B, Pretorius E, de Villiers WJS, Engelbrecht AM. Molecular regulation of autophagy in a proinflammatory tumour microenvironment: new insight into the role of serum amyloid A. Cytokine Growth Factor Rev. 2021;59:71-83. https://doi.org/10.1016/j.cytogfr.2021.01.007.

24. Wang K, Kim MK, Di Caro G, Wong J, Shalapour S, Wan J, et al. Interleukin-17 receptor A signaling in transformed enterocytes promotes early colorectal tumorigenesis. Immunity. 2014;41:1052-63. https://doi.org/10.1016/j.immuni.2014.11. 009.

25. Beneforti L, Dander E, Bresolin S, Bueno C, Acunzo D, Bertagna $\mathrm{M}$, et al. Pro-inflammatory cytokines favor the emergence of ETV6-RUNX1-positive pre-leukemic cells in a model of mesenchymal niche. British J Haematol. 2020;190:262-73. https:// doi.org/10.1111/bjh.16523.

26. Huang X, Tian Y, Shi W, Chen J, Yan L, Ren L, et al. Role of inflammation in the malignant transformation of pleural mesothelial cells induced by multi-walled carbon nanotubes. Nanotoxicology. 2020;14:947-67. https://doi.org/10.1080/17435390. 2020.1777477.

27. Yoshida GJ. Regulation of heterogeneous cancer-associated fibroblasts: the molecular pathology of activated signaling pathways. J Exp Clin Cancer Res. 2020;39:112. https://doi.org/10. 1186/s13046-020-01611-0.

28. Voronov E, Apte RN. Targeting the tumor microenvironment by intervention in interleukin-1 biology. Curr Pharm Des. 2017;23:4893-905. https://doi.org/10.2174/138161282366617 0613080919.

29. D'Orazi G, Cordani M, Cirone M. Oncogenic pathways activated by pro-inflammatory cytokines promote mutant P53 stability: clue for novel anticancer therapies. Cell Mol Life Sci. 2021;78:1853-60. https://doi.org/10.1007/s00018-020-03677-7.

30. Ju X, Zhang H, Zhou Z, Chen M, Wang Q. Tumor-associated macrophages induce PD-L1 expression in gastric cancer cells through IL-6 and TNF-a signaling. Exp Cell Res. 2020;396:112315. https://doi.org/10.1016/j.yexcr.2020.112315.

31. Tang X, Cao T, Zhu Y, Zhang L, Chen J, Liu T, et al. PIM2 promotes hepatocellular carcinoma tumorigenesis and progression through activating NF-KB signaling pathway. Cell Death Dis. 2020;11:1-14. https://doi.org/10.1038/s41419-020-2700-0.

32. Muoio MG, Talia M, Lappano R, Sims AH, Vella V, Cirillo F, et al. Activation of the S100A7/RAGE pathway by IGF-1 contributes to angiogenesis in breast cancer. Cancers (Basel). 2021;13:621. https://doi.org/10.3390/cancers13040621.

33. Morris J, Gonzales CB, De La Chapa JJ, Cabang AB, Fountzilas $\mathrm{C}$, Patel M, et al. The highly pure neem leaf extract, SCNE, Inhibits tumorigenesis in oral squamous cell carcinoma via disruption of pro-tumor inflammatory cytokines and cell signaling. Front Oncol. 2019;9:890. https://doi.org/10.3389/fonc.2019. 00890 .
34. Deng X-X, Jiao Y-N, Hao H-F, Xue D, Bai C-C, Han S-Y. Taraxacum mongolicum extract inhibited malignant phenotype of triple-negative breast cancer cells in tumor-associated macrophages microenvironment through suppressing IL-10 / STAT3 / PD-L1 signaling pathways. J Ethnopharmacol. 2021;274:113978. https://doi.org/10.1016/j.jep.2021.113978.

35. Zhang X, Zeng Y, Qu Q, Zhu J, Liu Z, Ning W, et al. PD-L1 induced by IFN- $\gamma$ from Tumor-associated macrophages via the JAK/STAT3 and PI3K/AKT signaling pathways promoted progression of lung cancer. Int J Clin Oncol. 2017;22:1026-33. https://doi.org/10.1007/s10147-017-1161-7.

36. Kim EK, Choi E-J. Compromised MAPK signaling in human diseases: an update. Arch Toxicol. 2015;89:867-82. https://doi. org/10.1007/s00204-015-1472-2.

37. Pópulo H, Lopes JM, Soares P, The MTOR. Signalling pathway in human cancer. Int J Mol Sci. 1886-1918;2012:13. https:// doi.org/10.3390/ijms13021886.

38. Zhao X, Lin Y, Jiang B, Yin J, Lu C, Wang J, et al. Icaritin inhibits lung cancer-induced osteoclastogenesis by suppressing the expression of IL-6 and TNF-a and through AMPK/MTOR signaling pathway. Anticancer Drugs. 2020;31:1004-11. https://doi.org/10.1097/CAD.0000000000000976.

39. Varga J, Greten FR. Cell plasticity in epithelial homeostasis and tumorigenesis. Nat Cell Biol. 2017;19:1133-41. https:// doi.org/10.1038/ncb3611.

40. Chen X-J, Wei W-F, Wang Z-C, Wang N, Guo C-H, Zhou $\mathrm{C}-\mathrm{F}$, et al. A novel lymphatic pattern promotes metastasis of cervical cancer in a hypoxic tumour-associated macrophagedependent manner. Angiogenesis. 2021. https://doi.org/10. 1007/s10456-020-09766-2.

41. Joshi RS, Kanugula SS, Sudhir S, Pereira MP, Jain S, Aghi MK. The role of cancer-associated fibroblasts in tumor progression. Cancers (Basel). 2021;13:1399. https://doi.org/10. 3390/cancers 13061399.

42. Calon A, Lonardo E, Berenguer-Llergo A, Espinet E, Hernando-Momblona X, Iglesias M, et al. Stromal gene expression defines poor-prognosis subtypes in colorectal cancer. Nat Genet. 2015;47:320-9. https://doi.org/10.1038/ng.3225.

43. Hong D, Fritz AJ, Zaidi SK, van Wijnen AJ, Nickerson JA, Imbalzano AN, et al. Epithelial-to-mesenchymal transition and cancer stem cells contribute to breast cancer heterogeneity. $J$ Cell Physiol. 2018;233:9136-44. https://doi.org/10.1002/jcp. 26847.

44. Adekoya TO, Richardson RM. Cytokines and chemokines as mediators of prostate cancer metastasis. Int J Mol Sci. 2020;21:E4449. https://doi.org/10.3390/ijms21124449.

45. Powell IJ, Chinni SR, Reddy SS, Zaslavsky A, Gavande N. Proinflammatory cytokines and chemokines initiate multiple prostate cancer biologic pathways of cellular proliferation, heterogeneity and metastasis in a racially diverse population and underlie the genetic/biologic mechanism of racial disparity: update. Urologic Oncol: Seminars Original Investig. 2021;39:34-40. https://doi. org/10.1016/j.urolonc.2020.08.019.

46. Liongue, C.; Ward, A.C.; Duan, W.; Shigdar, S. Cytokine networks and cancer stem cells. In Cancer Stem Cells: Emerging Concepts and Future Perspectives in Translational Oncology, 1st ed. Babashah, S., Ed.; Publisher: Springer International Publishing: Cham, 2015; pp. 67-87 ISBN 978-3-319-21030-8.

47. Zhang S, Yang X, Wang L, Zhang C. Interplay between inflammatory tumor microenvironment and cancer stem cells. Oncol Lett. 2018;16:679-86. https://doi.org/10.3892/ol.2018.8716.

48. Fu L-Q, Du W-L, Cai M-H, Yao J-Y, Zhao Y-Y, Mou X-Z. The roles of tumor-associated macrophages in tumor angiogenesis and metastasis. Cellular Immunology. 2020;353:104119. https:// doi.org/10.1016/j.cellimm.2020.104119. 
49. Horiguchi H, Tsujimoto H, Shinomiya N, Matsumoto Y, Sugasawa $\mathrm{H}$, Yamori $\mathrm{T}$, et al. A potential role of adhesion molecules on lung metastasis enhanced by local inflammation. Anticancer Res. 2020;40:6171-8. https://doi.org/10.21873/anticanres.14637.

50. Xiong J, Wang H, Wang Q. Suppressive myeloid cells shape the tumor immune microenvironment. Advanced Biol. 2021;5:1900311. https://doi.org/10.1002/adbi.201900311.

51. Parker KH, Beury DW, Ostrand-Rosenberg S. Chapter three myeloid-derived suppressor cells: critical cells driving immune suppression in the tumor microenvironment. In Advances in Cancer Research; Wang X-Y, Fisher PB, Editors. Immunotherapy of Cancer; Academic Press. 2015;128 pp. 95-139, https://doi.org/ 10.1016/bs.acr.2015.04.002.

52. Samec M, Liskova A, Koklesova L, Mersakova S, Strnadel J, Kajo K, et al. Flavonoids targeting HIF-1: implications on cancer metabolism. Cancers. 2021;13:130. https://doi.org/10.3390/ cancers13010130.

53. Liskova A, Koklesova L, Samec M, Varghese E, Abotaleb M, Samuel SM, et al. Implications of flavonoids as potential modulators of cancer neovascularity. J Cancer Res Clin Oncol. 2020. https://doi.org/10.1007/s00432-020-03383-8.

54. Samec M, Liskova A, Koklesova L, Samuel SM, Zhai K, Buhrmann C, et al. Flavonoids against the Warburg Phenotypeconcepts of predictive, preventive and personalised medicine to cut the gordian knot of cancer cell metabolism. EPMA J. 2020;11:377-98. https://doi.org/10.1007/s13167-020-00217-y.

55. Liskova A, Koklesova L, Samec M, Smejkal K, Samuel SM, Varghese E, Abotaleb M, Biringer K, Kudela E, Danko J, et al.. Flavonoids in cancer metastasis. Cancers (Basel). 2020;12, https:// doi.org/10.3390/cancers12061498.

56. Siddiqui M, Abdellatif B, Zhai K, Liskova A, Kubatka P, Büsselberg D. Flavonoids Alleviate peripheral neuropathy induced by anticancer drugs. Cancers (Basel). 2021;13:1576. https://doi. org/10.3390/cancers 13071576 .

57. Liskova A, Samec M, Koklesova L, Samuel SM, Zhai K, AlIshaq RK, et al. Flavonoids against the SARS-CoV-2 Induced inflammatory storm. Biomed Pharmacother. 2021;138:111430. https://doi.org/10.1016/j.biopha.2021.111430.

58. Al-Ishaq RK, Abotaleb M, Kubatka P, Kajo K, Büsselberg D. Flavonoids and their anti-diabetic effects: cellular mechanisms and effects to improve blood sugar levels. Biomolecules. 2019;9:E430. https://doi.org/10.3390/biom9090430.

59. Abotaleb M, Samuel S, Varghese E, Varghese S, Kubatka P, Liskova A, et al. Flavonoids in cancer and apoptosis. Cancers. 2018;11:28. https://doi.org/10.3390/cancers11010028.

60. Kubatka P, Kello M, Kajo K, Kruzliak P, Výbohová D, Šmejkal K, et al. Zulli, A.; Gönciová, G.; Mojžiš, J.; et al. Young barley indicates antitumor effects in experimental breast cancer in vivo and in vitro. Nutr Cancer. 2016;68:611-21. https://doi.org/10. 1080/01635581.2016.1154577.

61. Kubatka P, Kapinová A, Kello M, Kruzliak P, Kajo K, Výbohová D, et al. Fruit peel polyphenols demonstrate substantial anti-tumour effects in the model of breast cancer. Eur J Nutr. 2016;55:955-65. https://doi.org/10.1007/s00394-015-0910-5.

62. Wang Q, Xie C, Xi S, Qian F, Peng X, Huang J, et al. Radioprotective effect of flavonoids on ionizing radiation-induced brain damage. Molecules. 2020;25:E5719. https://doi.org/10.3390/ molecules25235719.

63. Ahn-Jarvis JH, Parihar A, Doseff AI. Dietary flavonoids for immunoregulation and cancer: food design for targeting disease. Antioxidants (Basel). 2019;8:202. https://doi.org/10.3390/antio $\mathrm{x} 8070202$.

64. Leyva-López N, Gutierrez-Grijalva EP, Ambriz-Perez DL, Heredia JB. Flavonoids as cytokine modulators: a possible therapy for inflammation-related diseases. Int J Mol Sci. 2016;17:921. https://doi.org/10.3390/ijms17060921.
65. Bauer D, Redmon N, Mazzio E, Soliman KF. Apigenin inhibits $\mathrm{TNF} \alpha / \mathrm{IL}-1 \alpha$-induced CCL2 release through IKBK-Epsilon signaling in MDA-MB-231 human breast cancer cells. PLoS One. 2017;12:e175558. https://doi.org/10.1371/journal.pone.01755 58.

66. Ting H, Deep G, Kumar S, Jain AK, Agarwal C, Agarwal R. Beneficial effects of the naturally occurring flavonoid silibinin on the prostate cancer microenvironment: role of monocyte chemotactic protein-1 and immune cell recruitment. Carcinogenesis. 2016;37:589-99. https://doi.org/10.1093/carcin/bgw039.

67. Ting HJ, Deep G, Jain AK, Cimic A, Sirintrapun J, Romero LM, et al. Silibinin Prevents prostate cancer cell-mediated differentiation of naïve fibroblasts into cancer-associated fibroblast phenotype by targeting TGF B2. Mol Carcinog. 2015;54:730-41. https://doi.org/10.1002/mc.22135.

68. Hou S, Yuan Q, Yu N, Liu B, Huang G, Yuan X. Cardamonin attenuates chronic inflammation and tumorigenesis in colon. Cell Cycle. 2019;18:3275-87. https://doi.org/10.1080/15384 101.2019.1673620.

69. Khan H, Ullah H, Castilho PCMF, Gomila AS, D'Onofrio G, Filosa R, et al. Targeting NF-KB signaling pathway in cancer by dietary polyphenols. Crit Rev Food Sci Nutr. 2020;60:2790-800. https://doi.org/10.1080/10408398.2019.1661827.

70. Zhao S, Jiang Y, Zhao J, Li H, Yin X, Wang Y, et al. Quercetin3-methyl ether inhibits esophageal carcinogenesis by targeting the AKT/MTOR/P70S6K and MAPK pathways. Mol Carcinog. 2018;57:1540-52. https://doi.org/10.1002/mc.22876.

71. Jiang M, Zhou L-Y, Xu N, An Q. Hydroxysafflor yellow A inhibited lipopolysaccharide-induced non-small cell lung cancer cell proliferation, migration, and invasion by suppressing the PI3K/ AKT/MTOR and ERK/MAPK signaling pathways. Thorac Cancer. 2019;10:1319-33. https://doi.org/10.1111/1759-7714.13019.

72. Vuong T, Mallet J-F, Ouzounova M, Rahbar S, Hernandez-Vargas $\mathrm{H}$, Herceg $\mathrm{Z}$, et al. Role of a polyphenol-enriched preparation on chemoprevention of mammary carcinoma through cancer stem cells and inflammatory pathways modulation. $J$ Transl Med. 2016;14:13. https://doi.org/10.1186/s12967-016-0770-7.

73. Zhang X, Zhu J, Yan J, Xiao Y, Yang R, Huang R, et al. Systems pharmacology unravels the synergic target space and therapeutic potential of Rhodiola Rosea L. for non-small cell lung cancer. Phytomedicine. 2020;79:153326. https://doi.org/10.1016/j. phymed.2020.153326.

74. Bokhari RA, Tantowi NACA, Lau SF, Mohamed S. Java Tea (Orthosiphon Stamineus) protected against osteoarthritis by mitigating inflammation and cartilage degradation: a preclinical study. Inflammopharmacology. 2018;26:939-49. https://doi.org/ 10.1007/s10787-017-0432-2.

75. Kim B, Park B. Baohuoside I suppresses invasion of cervical and breast cancer cells through the downregulation of CXCR4 chemokine receptor expression. Biochemistry. 2014;53:7562-9. https://doi.org/10.1021/bi5011927.

76. Li C, Li J, Gong S, Huang M, Li R, Xiong G, et al. Targeting the ILK/YAP Axis by LFG-500 blocks epithelial-mesenchymal transition and metastasis. Acta Pharmacol Sin. in press;2021:1-13. https://doi.org/10.1038/s41401-021-00655-y.

77. Shukla K, Sonowal H, Saxena A, Ramana KV. Didymin by suppressing NF-KB activation prevents VEGF-induced angiogenesis in vitro and in vivo. Vascul Pharmacol. 2019;115:18-25. https:// doi.org/10.1016/j.vph.2019.01.002.

78. Xu P, Yan F, Zhao Y, Chen X, Sun S, Wang Y, et al. Green tea polyphenol EGCG attenuates MDSCs-mediated immunosuppression through canonical and non-canonical pathways in a 4T1 murine breast cancer model. Nutrients. 2020;12. https://doi.org/ 10.3390/nu12041042.

79. Qin S-K, Li Q, Xu JM, Liang J, Cheng Y, Fan Y, et al. Icaritininduced immunomodulatory efficacy in advanced hepatitis B 
Virus-related hepatocellular carcinoma: immunodynamic biomarkers and overall survival. Cancer Science. 2020;111:421831. https://doi.org/10.1111/cas.14641.

80. Kashyap D, Garg VK, Tuli HS, Yerer MB, Sak K, Sharma AK, Kumar M, Aggarwal V, Sandhu SS Fisetin and quercetin: promising flavonoids with chemopreventive potential. Biomolecules.2019;9, https://doi.org/10.3390/biom9050174.

81. Colapietro A, Mancini A, D’Alessandro AM, Festuccia C. Crocetin and crocin from saffron in cancer chemotherapy and chemoprevention. Anticancer Agents Med Chem. 2019;19:38-47. https://doi.org/10.2174/1871520619666181231112453.

82. Delmas D, Xiao J, Vejux A, Aires V. Silymarin and cancer: a dual strategy in both in chemoprevention and chemosensitivity. Molecules. 2020;25, https://doi.org/10.3390/molecules250920 09.

83. George VC, Dellaire G, Rupasinghe HPV. Plant flavonoids in cancer chemoprevention: role in genome stability. $J$ Nutr Biochem. 2017;45:1-14. https://doi.org/10.1016/j.jnutbio.2016.11. 007.

84. Kim DH, Khan H, Ullah H, Hassan STS, Šmejkal K, Efferth T, et al. MicroRNA targeting by quercetin in cancer treatment and chemoprotection. Pharmacol Res. 2019;147:104346. https://doi. org/10.1016/j.phrs.2019.104346.

85. Clere N, Faure S, Martinez MC, Andriantsitohaina R. Anticancer properties of flavonoids: roles in various stages of carcinogenesis. Cardiovasc Hematol Agents Med Chem. 2011;9:62-77. https://doi.org/10.2174/187152511796196498.

86. Murata M. Inflammation and cancer. Environ Health Prev Med. 2018;23:50. https://doi.org/10.1186/s12199-018-0740-1.

87. Ramos-Nino ME. The role of chronic inflammation in obesityassociated cancers. ISRN Oncology. 2013;2013:e697521. https:// doi.org/10.1155/2013/697521.

88. Dunn BK, Umar A, Richmond E. Introduction: cancer chemoprevention and its context. Seminars in Oncology. 2016;43:19-21. https://doi.org/10.1053/j.seminoncol.2015.11.002.

89. García-Lafuente A, Guillamón E, Villares A, Rostagno MA, Martínez JA. Flavonoids as anti-inflammatory agents: implications in cancer and cardiovascular disease. Inflamm. Res. 2009;58:537-52. https://doi.org/10.1007/s00011-009-0037-3.

90. Tao Y, Zhan S, Wang Y, Zhou G, Liang H, Chen X, et al. Baicalin, the major component of traditional Chinese medicine Scutellaria baicalensis induces colon cancer cell apoptosis through inhibition of oncomiRNAs. Scientific Reports. 2018;8:14477. https://doi.org/10.1038/s41598-018-32734-2.

91. Zhou T, Zhang A, Kuang G, Gong X, Jiang R, Lin D, et al. Baicalin inhibits the metastasis of highly aggressive breast cancer cells by reversing epithelial-to-mesenchymal transition by targeting $\beta$-catenin signaling. Oncol Rep. 2017;38:3599-607. https://doi. org/10.3892/or.2017.6011.

92. Halliday GM, Byrne SN, Damian DL. Ultraviolet A radiation: its role in immunosuppression and carcinogenesis. Semin Cutan Med Surg. 2011;30:214-21. https://doi.org/10.1016/j.sder.2011. 08.002 .

93. Sherwani MA, Yang K, Jani A, Abed RA, Taufique AK, Dosunmu TG, et al. Protective effect of baicalin against TLR4mediated UVA-induced skin inflammation. Photochem Photobiol. 2019;95:605-11. https://doi.org/10.1111/php.13021.

94. Wang C-Z, Zhang C-F, Luo Y, Yao H, Yu C, Chen L, et al. Baicalein, an enteric microbial metabolite, suppresses gut inflammation and cancer progression in ApcMin/+ mice. Clin Transl Oncol. 2020;22:1013-22. https://doi.org/10.1007/ s12094-019-02225-5.

95. McDowell, C.; Farooq, U.; Haseeb, M. Inflammatory bowel disease. In StatPearls; Publisher: StatPearls Publishing: Treasure Island (FL) 2021.
96. Axelrad JE, Lichtiger S, Yajnik V. Inflammatory bowel disease and cancer: the role of inflammation, immunosuppression, and cancer treatment. World J Gastroenterol. 2016;22:4794-801. https://doi.org/10.3748/wjg.v22.i20.4794.

97. Habtemariam S. Rutin as a Natural Therapy for Alzheimer's disease: insights into its mechanisms of action. Curr Med Chem. 2016;23:860-73. https://doi.org/10.2174/092986732366616 0217124333 .

98. Kwon KH, Murakami A, Tanaka T, Ohigashi H. Dietary rutin, but not its aglycone quercetin, ameliorates dextran sulfate sodium-induced experimental colitis in mice: attenuation of pro-inflammatory gene expression. Biochem Pharmacol. 2005;69:395-406. https://doi.org/10.1016/j.bcp.2004.10.015.

99. Zhang M-J, Su H, Yan J-Y, Li N, Song Z-Y, Wang H-J, et al. Chemopreventive effect of myricetin, a natural occurring compound, on colonic chronic inflammation and inflammation-driven tumorigenesis in mice. Biomed Pharmacother. 2018;97:1131-7. https://doi.org/10.1016/j.biopha.2017.11.018.

100. Zhang Y-S, Wang F, Cui S-X, Qu X-J. Natural dietary compound naringin prevents azoxymethane/dextran sodium sulfate-induced chronic colorectal inflammation and carcinogenesis in mice. Cancer Biol Ther. 2018;19:735-44. https://doi.org/10.1080/ 15384047.2018.1453971.

101. Vega-Millán CB, Dévora-Figueroa AG, Burgess JL, Beamer PI, Furlong M, Lantz RC, et al. Inflammation biomarkers associated with arsenic exposure by drinking water and respiratory outcomes in indigenous children from three Yaqui Villages in Southern Sonora, México. Environ Sci Pollut Res. 2021. https:// doi.org/10.1007/s11356-021-13070-x.

102. Riegsecker S, Wiczynski D, Kaplan MJ, Ahmed S. Potential benefits of green tea polyphenol EGCG in the prevention and treatment of vascular inflammation in rheumatoid arthritis. Life Sci. 2013;93:307-12. https://doi.org/10.1016/j.lfs.2013.07.006.

103. Yu N-H, Pei H, Huang Y-P, Li Y-F. (-)-Epigallocatechin-3-gallate inhibits arsenic-induced inflammation and apoptosis through suppression of oxidative stress in mice. Cell Physiol Biochem. 2017;41:1788-800. https://doi.org/10.1159/000471911.

104. Meeran SM, Akhtar S, Katiyar SK. Inhibition of UVB-induced skin tumor development by drinking green tea polyphenols is mediated through DNA repair and subsequent inhibition of inflammation. J Invest Dermatol. 2009;129:1258-70. https:// doi.org/10.1038/jid.2008.354.

105. Lamb A, Chen L-F. Role of the Helicobacter pylori-induced inflammatory response in the development of gastric cancer. J Cell Biochem. 2013;114:491-7. https://doi.org/10.1002/jcb. 24389.

106. Zhang X-Y, Zhang P-Y, Aboul-Soud MAM. From inflammation to gastric cancer: role of Helicobacter pylori. Oncol Lett. 2017;13:543-8. https://doi.org/10.3892/ol.2016.5506.

107. Siriviriyakul P, Werawatganon D, Phetnoo N, Somanawat K, Chatsuwan T, Klaikeaw N, et al. Genistein attenuated gastric inflammation and apoptosis in Helicobacter pylori-induced gastropathy in rats. BMC Gastroenterology. 2020;20:410. https:// doi.org/10.1186/s12876-020-01555-x.

108. Hajialyani M, Hosein Farzaei M, Echeverría J, Nabavi SM, Uriarte E, Sobarzo-Sánchez E Hesperidin as a neuroprotective agent: a review of animal and clinical evidence. Molecules. 2019;24, https://doi.org/10.3390/molecules24030648.

109. Francescone R, Hou V, Grivennikov SI. Cytokines, IBD and colitis-associated cancer. Inflamm Bowel Dis. 2015;21:409-18. https://doi.org/10.1097/MIB.0000000000000236.

110. Guazelli CFS, Fattori V, Ferraz CR, Borghi SM, Casagrande R, Baracat MM, et al. Antioxidant and anti-inflammatory effects of hesperidin methyl chalcone in experimental ulcerative colitis. Chem Biol Interact. 2021;333:109315. https://doi.org/10.1016/j. cbi.2020.109315. 
111. Comalada M, Camuesco D, Sierra S, Ballester I, Xaus J, Gálvez $\mathrm{J}$, et al. In vivo quercitrin anti-inflammatory effect involves release of quercetin, which inhibits inflammation through down-regulation of the NF-KappaB pathway. Eur J Immunol. 2005;35:584-92. https://doi.org/10.1002/eji.200425778.

112. Lin Y, Shi R, Wang X, Shen H-M. Luteolin, a flavonoid with potentials for cancer prevention and therapy. Curr Cancer Drug Targets. 2008;8:634-46.

113. Luo Y, Shang P, Li D. Luteolin: a flavonoid that has multiple cardio-protective effects and its molecular mechanisms. Front Pharmacol. 2017;8:692. https://doi.org/10.3389/fphar.2017. 00692.

114. Yao Z-H, Yao X-L, Zhang Y, Zhang S-F, Hu J-C. Luteolin could improve cognitive dysfunction by inhibiting neuroinflammation. Neurochem Res. 2018;43:806-20. https://doi.org/10.1007/ s11064-018-2482-2.

115. Beaver LM, Stemmy EJ, Schwartz AM, Damsker JM, Constant SL, Ceryak SM, et al. Lung inflammation, injury, and proliferative response after repetitive particulate hexavalent chromium exposure. Environ Health Perspect. 1896-1902;2009:117. https://doi.org/10.1289/ehp.0900715.

116. Pratheeshkumar P, Son Y-O, Divya SP, Roy RV, Hitron JA, Wang $\mathrm{L}$, et al. Luteolin inhibits $\mathrm{Cr}(\mathrm{VI})$-induced malignant cell transformation of human lung epithelial cells by targeting ROS mediated multiple cell signaling pathways. Toxicol Appl Pharmacol. 2014;281:230-41. https://doi.org/10.1016/j.taap.2014.10.008.

117. Pace E, Di Vincenzo S, Di Salvo E, Genovese S, Dino P, Sangiorgi C, et al. MiR-21 upregulation increases IL-8 expression and tumorigenesis program in airway epithelial cells exposed to cigarette smoke. J Cell Physiol. 2019;234:22183-94. https://doi. org/10.1002/jcp.28786.

118. Katiyar SK, Agarwal R, Mukhtar H. Inhibition of both stage I and stage II skin tumor promotion in SENCAR mice by a polyphenolic fraction isolated from green tea: inhibition depends on the duration of polyphenol treatment. Carcinogenesis. 1993;14:2641-3. https://doi.org/10.1093/carcin/14.12.2641.

119. Lahiri-Chatterjee M, Katiyar SK, Mohan RR, Agarwal R. A flavonoid antioxidant, silymarin, affords exceptionally high protection against tumor promotion in the SENCAR mouse skin tumorigenesis model. Cancer Res. 1999;59:622-32.

120. Wei H,Tye L, Bresnick E, Birt DF. Inhibitory effect of apigenin, a plant flavonoid, on epidermal ornithine decarboxylase and skin tumor promotion in mice. Cancer Res. 1990;50:499-502.

121. Granato M, Rizzello C, Gilardini Montani MS, Cuomo L, Vitillo M, Santarelli R, et al. Quercetin induces apoptosis and autophagy in primary effusion lymphoma cells by inhibiting PI3K/AKT/ MTOR and STAT3 signaling pathways. J Nutr Biochem. 2017;41:124-36. https://doi.org/10.1016/j.jnutbio.2016.12.011.

122. Zhu JF, Li ZJ, Zhang GS, Meng K, Kuang WY, Li J, et al. Icaritin shows potent anti-leukemia activity on chronic myeloid leukemia in vitro and in vivo by regulating MAPK/ERK/JNK and JAK2/ STAT3 /AKT signalings. PLoS One. 2011;6:e23720. https://doi. org/10.1371/journal.pone.0023720.

123. Peng H-L, Huang W-C, Cheng S-C, Liou C-J. Fisetin inhibits the generation of inflammatory mediators in interleukin-1 $\beta$ induced human lung epithelial cells by suppressing the NF-KB and ERK1/2 pathways. Int Immunopharmacol. 2018;60:202-10. https://doi.org/10.1016/j.intimp.2018.05.004.

124. Zhang X-J, Jia S-S. Fisetin inhibits laryngeal carcinoma through regulation of AKT/NF-KB/MTOR and ERK1/2 signaling pathways. Biomed Pharmacother. 2016;83:1164-74. https://doi.org/ 10.1016/j.biopha.2016.08.035.

125. Shi B, Wang L-F, Meng W-S, Chen L, Meng Z-L. Carnosic acid and fisetin combination therapy enhances inhibition of lung cancer through apoptosis induction. Int J Oncol. 2017;50:2123-35. https://doi.org/10.3892/ijo.2017.3970.
126. You Y, Wang R, Shao N, Zhi F, Yang Y. Luteolin suppresses tumor proliferation through inducing apoptosis and autophagy via MAPK activation in glioma. Onco Targets Ther. 2019;12:2383-96. https://doi.org/10.2147/OTT.S191158.

127. Song S, Su Z, Xu H, Niu M, Chen X, Min H, et al. Luteolin selectively kills STAT3 highly activated gastric cancer cells through enhancing the binding of STAT3 to SHP-1. Cell Death Dis. 2017;8:e2612. https://doi.org/10.1038/cddis.2017.38.

128. Jiang Z-B, Wang W-J, Xu C, Xie Y-J, Wang X-R, Zhang $\mathrm{Y}-\mathrm{Z}$, et al. Luteolin and its derivative apigenin suppress the inducible PD-L1 expression to improve anti-tumor immunity in KRAS-mutant lung cancer. Cancer Lett. 2021;515:36-48. https://doi.org/10.1016/j.canlet.2021.05.019.

129. Yang J, Pi C, Wang G. Inhibition of PI3K/Akt/MTOR pathway by apigenin induces apoptosis and autophagy in hepatocellular carcinoma cells. Biomed Pharmacother. 2018;103:699-707. https://doi.org/10.1016/j.biopha.2018.04.072.

130. Park C-H, Min S-Y, Yu H-W, Kim K, Kim S, Lee H-J, et al. Effects of apigenin on RBL-2H3, RAW264.7, and HaCaT cells: anti-allergic, anti-inflammatory, and skin-protective activities. Int J Mol Sci. 2020;21:E4620. https://doi.org/10.3390/ijms2 1134620

131. Qiu J-G, Wang L, Liu W-J, Wang J-F, Zhao E-J, Zhou F-M, et al. Apigenin inhibits IL-6 transcription and suppresses esophageal carcinogenesis. Front Pharmacol. 2019;10:1002. https://doi.org/10.3389/fphar.2019.01002.

132. Hara S, Morita R, Ogawa T, Segawa R, Takimoto N, Suzuki $\mathrm{K}$, et al. Tumor suppression effects of bilberry extracts and enzymatically modified isoquercitrin in early preneoplastic liver cell lesions induced by piperonyl butoxide promotion in a two-stage rat hepatocarcinogenesis model. Exp Toxicol Pathol. 2014;66:225-34. https://doi.org/10.1016/j.etp.2014.02.002.

133. Chen L, Guo D. The functions of tumor suppressor PTEN in innate and adaptive immunity. Cell Mol Immunol. 2017;14:581-9. https://doi.org/10.1038/cmi.2017.30.

134. Zhao Z, Liu B, Sun J, Lu L, Liu L, Qiu J, et al. Scutellaria flavonoids effectively inhibit the malignant phenotypes of nonsmall cell lung cancer in an Id1-dependent manner. Int J Biol Sci. 2019;15:1500-13. https://doi.org/10.7150/ijbs.33146.

135. Ke M, Zhang Z, Xu B, Zhao S, Ding Y, Wu X, et al. Baicalein and baicalin promote antitumor immunity by suppressing PD-L1 expression in hepatocellular carcinoma cells. Int Immunopharmacol. 2019;75:105824. https://doi.org/10.1016/j. intimp.2019.105824.

136. Bucio-Noble D, Kautto L, Krisp C, Ball MS, Molloy MP. Polyphenol extracts from dried sugarcane inhibit inflammatory mediators in an in vitro colon cancer model. $J$ Proteomics. 2018;177:1-10. https://doi.org/10.1016/j.jprot.2018.02.009.

137. Basak SK, Bera A, Yoon AJ, Morselli M, Jeong C, Tosevska A, et al. A randomized, phase 1, placebo-controlled trial of APG157 in oral cancer demonstrates systemic absorption and an inhibitory effect on cytokines and tumor-associated microbes. Cancer. 2020:126, 1668-1682. https://doi.org/10.1002/cncr. 32644.

138. Farsad-Naeimi A, Alizadeh M, Esfahani A, Darvish Aminabad E. Effect of fisetin supplementation on inflammatory factors and matrix metalloproteinase enzymes in colorectal cancer patients. Food Funct. 2018;9:2025-31. https://doi.org/10.1039/ c7fo01898c.

139. Henning SM, Wang P, Said JW, Huang M, Grogan T, Elashoff $\mathrm{D}$, et al. Randomized clinical trial of brewed green and black tea in men with prostate cancer prior to prostatectomy. Prostate. 2015;75:550-9. https://doi.org/10.1002/pros.22943.

140. Lesinski, G.B.; Reville, P.K.; Mace, T.A.; Young, G.S.; Ahn-Jarvis, J.; Thomas-Ahner, J.; Vodovotz, Y.; Ameen, Z.; Grainger, E.; Riedl, K.; et al. Consumption of soy isoflavone 
enriched bread in men with prostate cancer is associated with reduced proinflammatory cytokines and immunosuppressive cells. Cancer Prev Res (Phila) 2015, 8, 1036-1044, https:// doi.org/10.1158/1940-6207.CAPR-14-0464.

141. Shike M, Doane AS, Russo L, Cabal R, Reis-Filho JS, Gerald $\mathrm{W}$, et al. The effects of soy supplementation on gene expression in breast cancer: a randomized placebo-controlled study. J Natl Cancer Inst. 2014;106:dju189. https://doi.org/10.1093/ jnci/dju 189.

142. Dong W, Chen A, Chao X, Li X, Cui Y, Xu C, et al. Chrysin inhibits proinflammatory factor-induced EMT phenotype and cancer stem cell-like features in HeLa cells by blocking the NF-KB/Twist axis. Cell Physiol Biochem. 2019;52:1236-50. https://doi.org/10.33594/000000084.

143. Yan Y, Liu X, Gao J, Wu Y, Li Y. Inhibition of TGF- $\beta$ signaling in gliomas by the flavonoid diosmetin isolated from Dracocephalum peregrinum L. Molecules. 2020;25:192. https://doi.org/10. 3390/molecules25010192.

144. Wang Y, Li J-J, Chen Y-M. Biochanin A extirpates the epithelialmesenchymal transition in a human lung cancer. Exp Ther Med. 2018;15:2830-6. https://doi.org/10.3892/etm.2018.5731.

145. Li J, Wang T, Liu P, Yang F, Wang X, Zheng W, et al. Hesperetin ameliorates hepatic oxidative stress and inflammation via the PI3K/AKT-Nrf2-ARE pathway in oleic acid-induced HepG2 cells and a rat model of high-fat diet-induced NAFLD. Food Funct. 2021;12:3898-918. https://doi.org/10.1039/d0fo02736g.

146. Wei R, Cortez Penso NE, Hackman RM, Wang Y, Mackenzie GG. Epigallocatechin-3-gallate (EGCG) suppresses pancreatic cancer cell growth, invasion, and migration partly through the inhibition of akt pathway and epithelial-mesenchymal transition: enhanced efficacy when combined with gemcitabine. Nutrients. 1856;2019:11. https://doi.org/10.3390/nu11081856.

147. Kang HR, Moon JY, Ediriweera MK, Song YW, Cho M, Kasiviswanathan $\mathrm{D}$, et al. Dietary Flavonoid myricetin inhibits invasion and migration of radioresistant lung cancer cells (A549-IR) by suppressing MMP-2 and MMP-9 expressions through inhibition of the FAK-ERK signaling pathway. Food Sci Nutr. 2020;8:2059-67. https://doi.org/10.1002/fsn3.1495.

148. Tuponchai P, Kukongviriyapan V, Prawan A, Kongpetch S, Senggunprai L. Myricetin ameliorates cytokine-induced migration and invasion of cholangiocarcinoma cells via suppression of STAT3 pathway. J Cancer Res Ther. 2019;15:157-63. https://doi. org/10.4103/jcrt.JCRT_287_17.

149. Gu Y, Yu J, Ding C, Zhou Y, Yang J, Yu W, et al. Flavonoid GL-V9 suppresses invasion and migration of human colorectal cancer cells by inhibiting PI3K/Akt and MMP-2/9 signaling. $J$ Cancer. 2021;12:4542-51. https://doi.org/10.7150/jca.58710.

150. Susmitha GD, Miyazato K, Ogura K, Yokoyama S, Hayakawa Y. Anti-metastatic effects of baicalein by targeting STAT3 activity in breast cancer cells. Biol Pharm Bull. 1899-1905;2020:43. https://doi.org/10.1248/bpb.b20-00571.

151. Salama AAA, Allam RM. Promising targets of chrysin and daidzein in colorectal cancer: amphiregulin, CXCL1, and MMP-9. Eur J Pharmacol. 2021;892:173763. https://doi.org/10.1016/j. ejphar.2020.173763.

152. Ko Y-C, Choi HS, Liu R, Kim J-H, Kim S-L, Yun B-S, et al. Inhibitory effects of tangeretin, a citrus peel-derived flavonoid, on breast cancer stem cell formation through suppression of Stat3 signaling. Molecules. 2020;25:2599. https://doi.org/10.3390/ molecules25112599.

153. Sun S, Cui Y, Ren K, Quan M, Song Z, Zou H, et al. 8-Bromo7-methoxychrysin reversed M2 polarization of tumor-associated macrophages induced by liver cancer stem-like cells. Anticancer Agents Med Chem. 2017;17:286-93. https://doi.org/10.2174/ 1871520616666160204112556.
154. Gong G, Wang H, Kong X, Duan R, Dong TTX, Tsim KWK. Flavonoids are identified from the extract of Scutellariae Radix to suppress inflammatory-induced angiogenic responses in cultured RAW 264.7 Macrophages. Sci Rep. 2018;8:17412. https://doi. org/10.1038/s41598-018-35817-2.

155. Li C, Wang Q, Shen S, Wei X, Li G. HIF-1 $\alpha /$ VEGF Signalingmediated epithelial-mesenchymal transition and angiogenesis is critically involved in anti-metastasis effect of luteolin in melanoma cells. Phytother Res. 2019;33:798-807. https://doi. org/10.1002/ptr.6273.

156. Mirzaaghaei S, Foroughmand AM, Saki G, Shafiei M. Combination of epigallocatechin-3-gallate and silibinin: a novel approach for targeting both tumor and endothelial cells. ACS Omega. 2019;4:8421-30. https://doi.org/10.1021/acsomega. $9 \mathrm{~b} 00224$.

157. Tsai C-H, Tzeng S-F, Hsieh S-C, Yang Y-C, Hsiao Y-W, Tsai $\mathrm{M}-\mathrm{H}$, et al. A standardized herbal extract mitigates tumor inflammation and augments chemotherapy effect of docetaxel in prostate cancer. Sci Rep. 2017;7:15624. https://doi.org/10.1038/ s41598-017-15934-0.

158. Ishak NIM, Mohamed S, Madzuki IN, Mustapha NM, Esa NM. Limonin modulated immune and inflammatory responses to suppress colorectal adenocarcinoma in mice model. Naunyn Schmiedebergs Arch Pharmacol. 2021. https://doi.org/10.1007/ s00210-021-02101-6.

159. McLarty J, Bigelow RLH, Smith M, Elmajian D, Ankem M, Cardelli JA. Tea polyphenols decrease serum levels of prostatespecific antigen, hepatocyte growth factor, and vascular endothelial growth factor in prostate cancer patients and inhibit production of hepatocyte growth factor and vascular endothelial growth factor in vitro. Cancer Prev Res (Phila). 2009;2:673-82. https:// doi.org/10.1158/1940-6207.CAPR-08-0167.

160. Sturgeon KM, Foo W, Heroux M, Schmitz K. Change in inflammatory biomarkers and adipose tissue in BRCA1/2 breast cancer survivors following a yearlong lifestyle modification program. Cancer Prev Res. 2018;11:545-50.

161. Qian S, Golubnitschaja O, Zhan X. Chronic inflammation: key player and biomarker-set to predict and prevent cancer development and progression based on individualized patient profiles. EPMA J. 2019;10:365-81. https://doi.org/10.1007/ s13167-019-00194-X

162. U.S. Department of Agriculture, Agricultural Research Service. USDA National Nutrient Database for the Flavonoid Content of Selected Foods, Release 3.0. 2011. [(Accessed on 2 June 2013)]. Available Online: . Available online: http://www.ars. usda.gov/SP2UserFiles/Place/12354500/Data/Flav/Flav_R03. pdf (accessed on 5 June 2020).

163. Showing All Foods in Which the Polyphenol Myricetin Is Found - Phenol-Explorer Available online: http://phenol-explorer.eu/ contents/polyphenol/309 (accessed on 9 September 2021).

164. Showing All Foods in Which the Polyphenol Biochanin A Is Found - Phenol-Explorer Available online: http://phenolexplorer.eu/contents/polyphenol/397 (accessed on 9 September 2021).

165. Showing Details for Content Value of Baicalein in Welsh Onion, Fresh - Phenol-Explorer Available online: http://phenol-explorer. eu/contents/show/2/266/477 (accessed on 9 September 2021).

166. U.S. Department of Agriculture, Agricultural Research Service. USDA National Nutrient Database for the Isoflavone Content of Selected Foods, Release 2.0. 2008. [(Accessed on 2 June 2013)]. Available Online: Available online: http://www.ars.usda. gov/SP2UserFiles/Place/12354500/Data/isoflav/Isoflav_R2.pdf. (accessed on 5 June 2020).

167. Showing All Foods in Which the Polyphenol Tangeretin Is Found - Phenol-Explorer Available online: http://phenolexplorer.eu/contents/polyphenol/238?fbclid=IwAR130SQ 
vsBI-XtgGjasfPVGpmFb60_MqoJVyzVMbqR07vFQIoxTQwAwmIhk (accessed on 9 September 2021).

168. Showing All Foods in Which the Polyphenol Genistin Is Found - Phenol-Explorer Available online: http://phenol-explorer.eu/ contents/polyphenol/404 (accessed on 9 September 2021).

169. Showing All Foods in Which the Polyphenol Diosmin Is Found - Phenol-Explorer Available online: http://phenol-explorer.eu/ contents/polyphenol/232 (accessed on 9 September 2021).

170. Showing All Foods in Which the Polyphenol Luteolin Is Found - Phenol-Explorer Available online: http://phenol-explorer.eu/ contents/polyphenol/229 (accessed on 9 September 2021).

171. Kucera R, Pecen L, Topolcan O, Dahal AR, Costigliola V, Giordano FA, et al. Prostate cancer management: long-term beliefs, epidemic developments in the early twenty first century and 3PM dimensional solutions. EPMA J. 2020. https://doi.org/ 10.1007/s13167-020-00214-1.

172. Golubnitschaja O, Liskova A, Koklesova L, Samec M, Biringer K, Büsselberg D, Podbielska H, Kunin AA, Evsevyeva ME, Shapira N, et al. Caution, "Normal" BMI: health risks associated with potentially masked individual underweight-EPMA position paper. EPMA J. 2021;2021:1-22. https://doi.org/10.1007/ s13167-021-00251-4.

173. Wang W, Yan Y, Guo Z, Hou H, Garcia M, Tan X, Anto E, et al. All around suboptimal health. A Joint Position Paper of the Suboptimal Health Study Consortium and European Association for Predictive, Preventive and Personalised Medicine. EMPA J. 2021, accepted.

174. Torres Crigna A, Link B, Samec M, Giordano FA, Kubatka P, Golubnitschaja O Endothelin-1 axes in the framework of predictive, preventive and personalised (3P) medicine. EPMA J. 2021:1-41, https://doi.org/10.1007/s13167-021-00248-z.

175. Flammer Syndrome: From Phenotype to Associated Pathologies, Prediction, Prevention and Personalisation; Golubnitschaja, O., Ed.; Advances in predictive, preventive and personalised medicine; Springer International Publishing: Cham, 2019; Vol. 11; ISBN 978-3-030-13549-2.

176. Marranzano M, Ray S, Godos J, Galvano F. Association between dietary flavonoids intake and obesity in a cohort of adults living in the Mediterranean area. Int J Food Sci Nutr. 2018;69:1020-9. https://doi.org/10.1080/09637486.2018.1452900.

177. Kapinova A, Stefanicka P, Kubatka P, Zubor P, Uramova S, Kello $\mathrm{M}$, et al. Are plant-based functional foods better choice against cancer than single phytochemicals? a Critical Review of Current Breast Cancer Research. Biomed Pharmacother. 2017;96:146577. https://doi.org/10.1016/j.biopha.2017.11.134.

178. Akhlaghi M, Ghobadi S, Mohammad Hosseini M, Gholami Z, Mohammadian F. Flavanols are potential anti-obesity agents, a systematic review and meta-analysis of controlled clinical trials. Nutr Metab Cardiovasc Dis. 2018;28:675-90. https://doi.org/10. 1016/j.numecd.2018.04.001.

179. García-Barrado MJ, Iglesias-Osma MC, Pérez-García E, Carrero $\mathrm{S}$, Blanco EJ, Carretero-Hernández $\mathrm{M}$, et al. Role of flavonoids in the interactions among obesity, inflammation, and autophagy. Pharmaceuticals (Basel). 2020;13:342. https://doi.org/10.3390/ ph13110342.

180. Gentile D, Fornai M, Colucci R, Pellegrini C, Tirotta E, Benvenuti $\mathrm{L}$, et al. The flavonoid compound apigenin prevents colonic inflammation and motor dysfunctions associated with high fat diet-induced obesity. PLoS One. 2018;13:e195502. https://doi. org/10.1371/journal.pone.0195502.

181. Baek Y, Lee MN, Wu D, Pae M. Luteolin reduces adipose tissue macrophage inflammation and insulin resistance in postmenopausal obese mice. J Nutr Biochem. 2019;71:72-81. https://doi. org/10.1016/j.jnutbio.2019.06.002.

182. Lee M, Sorn SR, Park Y, Park H-K. Anthocyanin rich-black soybean testa improved visceral fat and plasma lipid profiles in overweight/obese korean adults: a randomized controlled trial. $J$ Med Food. 2016;19:995-1003. https://doi.org/10.1089/jmf.2016. 3762.

183. Li D, Zhang Y, Liu Y, Sun R, Xia M. Purified anthocyanin supplementation reduces dyslipidemia, enhances antioxidant capacity, and prevents insulin resistance in diabetic patients. $J$ Nutr. 2015;145:742-8. https://doi.org/10.3945/jn.114.205674.

184. Arcidiacono B, Iiritano S, Nocera A, Possidente K, Nevolo MT, Ventura V, et al. Insulin resistance and cancer risk: an overview of the pathogenetic mechanisms. Exp Diabetes Res. 2012;2012:789174. https://doi.org/10.1155/2012/789174.

185. Spencer JPE. Flavonoids and brain health: multiple effects underpinned by common mechanisms. Genes Nutr. 2009;4:243-50. https://doi.org/10.1007/s12263-009-0136-3.

186. Wang J, Cheng C, Xin C, Wang Z. The antidepressant-like effect of flavonoids from Trigonella Foenum-Graecum seeds in chronic restraint stress mice via modulation of monoamine regulatory pathways. Molecules. 2019;24:1105. https://doi.org/ 10.3390/molecules24061105.

187. Sarriá B, Martínez-López S, Sierra-Cinos JL, García-Diz L, Mateos R, Bravo L. Regular consumption of a cocoa product improves the cardiometabolic profile in healthy and moderately Hypercholesterolaemic Adults. Br J Nutr. 2014;111:122-34. https://doi.org/10.1017/S000711451300202X.

188. Mellor DD, Madden LA, Smith KA, Kilpatrick ES, Atkin SL. High-polyphenol chocolate reduces endothelial dysfunction and oxidative stress during acute transient hyperglycaemia in type 2 diabetes: a pilot randomized controlled trial. Diabet Med. 2013;30:478-83. https://doi.org/10.1111/dme.12030.

189. Ciumărnean L, Milaciu MV, Runcan O, Vesa ȘC, Răchişan AL, Negrean V, et al. The effects of flavonoids in cardiovascular diseases. Molecules. 2020;25:4320. https://doi.org/10.3390/ molecules25184320.

190. Mastantuono T, Battiloro L, Sabatino L, Chiurazzi M, Di Maro M, Muscariello E, et al. Effects of citrus flavonoids against microvascular damage induced by hypoperfusion and reperfusion in rat pial circulation. Microcirculation. 2015;22:378-90. https://doi.org/10.1111/micc.12207.

191. de Albuquerque RDDG, Perini JA, Machado DE, AngeliGamba T, Esteves R. dos S.; Santos, M.G.; Oliveira, A.P.; Rocha, L. Wound healing activity and chemical standardization of Eugenia Pruniformis Cambess. Pharmacogn Mag. 2016;12:288-94. https://doi.org/10.4103/0973-1296.192206.

192. Antunes-Ricardo M, Gutiérrez-Uribe J, Serna-Saldívar SO. Anti-inflammatory glycosylated flavonoids as therapeutic agents for treatment of diabetes-impaired wounds. Curr Top Med Chem. 2015;15:2456-63. https://doi.org/10.2174/15680 26615666150619141702.

193. Olas B. Honey and its phenolic compounds as an effective natural medicine for cardiovascular diseases in humans? Nutrients. 2020;12:283. https://doi.org/10.3390/nu12020283.

194. Efem SE. Clinical observations on the wound healing properties of honey. Br J Surg. 1988;75:679-81. https://doi.org/10. 1002/bjs. 1800750718.

195. Henriques A, Jackson S, Cooper R, Burton N. Free radical production and quenching in honeys with wound healing potential. J Antimicrob Chemother. 2006;58:773-7. https://doi.org/10. 1093/jac/dk1336.

196. Atrahimovich D, Avni D, Khatib S. Flavonoids-macromolecules interactions in human diseases with focus on Alzheimer, atherosclerosis and cancer. Antioxidants (Basel). 2021;10:423. https://doi.org/10.3390/antiox 10030423.

197. Ginwala R, Bhavsar R, Chigbu DI, Jain P, Khan ZK. Potential role of flavonoids in treating chronic inflammatory diseases with a special focus on the anti-inflammatory activity of 
apigenin. Antioxidants (Basel). 2019;8:E35. https://doi.org/10. 3390/antiox8020035.

198. Rodríguez-García C, Sánchez-Quesada C, Gaforio JJ. Dietary flavonoids as cancer chemopreventive agents: an updated review of human studies. Antioxidants (Basel). 2019;8, https:// doi.org/10.3390/antiox8050137.

199. Jenkins DJA, Kendall CWC, Connelly PW, Jackson C-JC, Parker T, Faulkner D, et al. Effects of high- and low-isoflavone (Phytoestrogen) soy foods on inflammatory biomarkers and proinflammatory cytokines in middle-aged men and women. Metabolism. 2002;51:919-24. https://doi.org/10.1053/meta. 2002.33352.

200. Toledo E, Salas-Salvadó J, Donat-Vargas C, Buil-Cosiales P, Estruch R, Ros E, et al. Mediterranean diet and invasive breast cancer risk among women at high cardiovascular risk in the PREDIMED trial: a randomized clinical trial. JAMA Intern Med. 2015;175:1752-60. https://doi.org/10.1001/jamainternmed.2015. 4838.

201. Castelló A, Pollán M, Buijsse B, Ruiz A, Casas AM, BaenaCañada JM, et al. Spanish Mediterranean diet and other dietary patterns and breast cancer risk: case-control EpiGEICAM study. British J Cancer. 2014;111:1454-62. https://doi.org/10.1038/bjc. 2014.434

202. Gerner C, Costigliola V, Golubnitschaja O. Multiomic patterns in body fluids: technological challenge with a great potential to implement the advances paradigm of 3P medicine. Mass Spectrom Rev.2019.https://doi.org/10.1002/mas.21612.

203. Bubnov R, Polivka J, Zubor P, Konieczka K, Golubnitschaja O. Pre-metastatic niches in breast cancer: are they created by or prior to the tumour onset? "Flammer Syndrome" Relevance to Address the Question. EPMA J. 2017;8:141-57. https://doi.org/ 10.1007/s13167-017-0092-8.

204. Goldstein E, Yeghiazaryan K, Ahmad A, Giordano FA, Fröhlich H, Golubnitschaja O. Optimal multiparametric set-up modelled for best survival outcomes in palliative treatment of liver malignancies: unsupervised machine learning and 3 PM recommendations. EPMA J. 2020;11:505-15. https://doi.org/10.1007/ s13167-020-00221-2.

205. Ferraz CR, Carvalho TT, Manchope MF, Artero NA, RasquelOliveira FS, Fattori V, et al. Therapeutic potential of flavonoids in pain and inflammation: mechanisms of action, pre-clinical and clinical data, and pharmaceutical development. Molecules. 2020;25:762. https://doi.org/10.3390/molecules25030762.

206. Bosch-Barrera J, Corominas-Faja B, Cuyàs E, Martin-Castillo B, Brunet J, Menendez JA. Silibinin administration improves hepatic failure due to extensive liver infiltration in a breast cancer patient. Anticancer Res. 2014;34:4323-7.

207. Harati K, Behr B, Wallner C, Daigeler A, Hirsch T, Jacobsen $\mathrm{F}$, et al. Anti-proliferative activity of epigallocatechin-3-gallate and silibinin on soft tissue sarcoma cells. Mol Med Rep. 2017;15:103-10. https://doi.org/10.3892/mmr.2016.5969.

208. Sakai H, Tabata S, Kimura M, Yabe S, Isa Y, Kai Y, et al. Active ingredients of Hange-Shashin-to, baicalelin and 6-gingerol, inhibit 5-fluorouracil-induced upregulation of CXCL1 in the colon to attenuate diarrhea development. Biol Pharm Bull. 2017;40:2134-9. https://doi.org/10.1248/bpb.b17-00479.

209. Samare-Najaf M, Zal F, Safari S, Koohpeyma F, Jamali N. Stereological and histopathological evaluation of doxorubicin-induced toxicity in female rats' ovary and uterus and palliative effects of quercetin and vitamin E. Hum Exp Toxicol. 2020;39:1710-24. https://doi.org/10.1177/0960327120937329.

210. Ehsan N, Ijaz MU, Ashraf A, Sarwar S, Samad A, Afzal G, et al. Mitigation of cisplatin induced nephrotoxicity by casticin in male albino rats. Braz J Biol. 2021;83:e243438. https://doi.org/ 10.1590/1519-6984.243438.
211. Leong DJ, Choudhury M, Hanstein R, Hirsh DM, Kim SJ, Majeska RJ, et al. Green tea polyphenol treatment is chondroprotective, anti-inflammatory and palliative in a mouse posttraumatic osteoarthritis model. Arthritis Res Ther. 2014;16:508. https://doi.org/10.1186/s13075-014-0508-y.

212. Kaswan NK, Mohammed Izham NAB, Tengku Mohamad TAS, Sulaiman MR, Perimal EK. Cardamonin modulates neuropathic pain through the possible involvement of serotonergic 5-HT1A receptor pathway in CCI-induced neuropathic pain mice model. Molecules. 2021;26:3677. https://doi.org/10.3390/molecules2 6123677.

213. Siracusa R, Monaco F, D’Amico R, Genovese T, Cordaro M, Interdonato L, et al. Epigallocatechin-3-gallate modulates postoperative pain by regulating biochemical and molecular pathways. Int J Mol Sci. 2021;22:6879. https://doi.org/10.3390/ijms2 2136879.

214. Warden BA, Smith LS, Beecher GR, Balentine DA, Clevidence BA. Catechins are bioavailable in men and women drinking black tea throughout the day. J Nutr. 2001;131:1731-7. https://doi.org/ 10.1093/jn/131.6.1731.

215. Kim JK, Park SU. Quercetin and its role in biological functions: an updated review. EXCLI J. 2018;17:856-63. https://doi.org/10. 17179/excli2018-1538.

216. Seifirad S, Haghpanah V. Inappropriate modeling of chronic and complex disorders: how to reconsider the approach in the context of predictive, preventive and personalized medicine, and translational medicine. EPMA J. 2019;10:195-209. https://doi.org/10. 1007/s13167-019-00176-z.

217. Wang S, DeGroff VL, Clinton SK. Tomato and soy polyphenols reduce insulin-like growth factor-I-stimulated rat prostate cancer cell proliferation and apoptotic resistance in vitro via inhibition of intracellular signaling pathways involving tyrosine kinase. $J$ Nutr. 2003;133:2367-76. https://doi.org/10.1093/jn/133.7.2367.

218. Miltyk W, Craciunescu CN, Fischer L, Jeffcoat RA, Koch MA, Lopaczynski W, et al. Lack of significant genotoxicity of purified soy isoflavones (genistein, daidzein, and glycitein) in 20 patients with prostate cancer. Am J Clin Nutr. 2003;77:875-82. https:// doi.org/10.1093/ajen/77.4.875.

219. Napora JK, Short RG, Muller DC, Carlson OD, Odetunde JO, $\mathrm{Xu} \mathrm{X}$, et al. High dose isoflavones do not improve metabolic and inflammatory parameters in androgen deprived men with prostate cancer. J Androl. 2011;32:40-8. https://doi.org/10.2164/jandrol. 110.010983 .

220. Hamilton-Reeves JM, Banerjee S, Banerjee SK, Holzbeierlein JM, Thrasher JB, Kambhampati S, et al. Short-term soy isoflavone intervention in patients with localized prostate cancer: a randomized, double-blind, placebo-controlled trial. PLoS One. 2013;8:e68331. https://doi.org/10.1371/journal.pone.0068331.

221. Wang P, Aronson WJ, Huang M, Zhang Y, Lee R-P, Heber D, et al. Green tea polyphenols and metabolites in prostatectomy tissue: implications for cancer prevention. Cancer Prev Res (Phila). 2010;3:985-93. https://doi.org/10.1158/1940-6207. CAPR-09-0210.

222. Wang Z, Desmoulin S, Banerjee S, Kong D, Li Y, Deraniyagala $\mathrm{RL}$, et al. Synergistic effects of multiple natural products in pancreatic cancer cells. Life Sci. 2008;83:293-300. https://doi.org/ 10.1016/j.lfs.2008.06.017.

223. Dominiak K, McKinney J, Heilbrun LK, Sarkar FH. Critical need for clinical trials: an example of a pilot human intervention trial of a mixture of natural agents protecting lymphocytes against TNF- $\alpha$ induced activation of NF-KB. Pharm Res. 2010;27, https://doi.org/10.1007/s11095-010-0113-y.

224. Karamać M. Chelation of $\mathrm{Cu}(\mathrm{II}), \mathrm{Zn}(\mathrm{II})$, and $\mathrm{Fe}(\mathrm{II})$ by tannin constituents of selected edible nuts. Int J Mol Sci. 2009;10:548597. https://doi.org/10.3390/ijms10125485. 
225. Harper CE, Patel BB, Wang J, Lamartiniere CA. Epigallocatechin-3-gallate (EGCG) down-regulates the androgen receptor and the IGF pathway in the prostate of TRAMP mice. Cancer Res. 2006;66:1148-8.
Publisher's note Springer Nature remains neutral with regard to jurisdictional claims in published maps and institutional affiliations.

\section{Authors and Affiliations}

\section{Peter Kubatka ${ }^{1}$ Alena Mazurakova ${ }^{2} \cdot$ Marek Samec $^{3} \cdot$ Lenka Koklesova $^{2} \cdot$ Kevin Zhai $^{4} \cdot$ Raghad AL-Ishaq $^{4}$. Karol Kajo ${ }^{5}$ Kamil Biringer ${ }^{2}$ - Desanka Vybohova ${ }^{6}$. Aranka Brockmueller ${ }^{7} \cdot$ Martin Pec $^{1} \cdot$ Mehdi Shakibaei $^{7}$. Frank A. Giordano ${ }^{8}$. Dietrich Büsselberg ${ }^{4}$. Olga Golubnitschaja ${ }^{9}$}

\author{
Alena Mazurakova \\ liskova80@uniba.sk \\ Marek Samec \\ marek.samec@uniba.sk \\ Lenka Koklesova \\ koklesova5@uniba.sk \\ Kevin Zhai \\ kez4003@qatar.med.cornell.edu \\ Raghad AL-Ishaq \\ rkmalishaq@ hotmail.com \\ Karol Kajo \\ kkajo@ousa.sk \\ Kamil Biringer \\ kamil.biringer@uniba.sk \\ Desanka Vybohova \\ desanka.vybohova@uniba.sk \\ Aranka Brockmueller \\ Aranka.Brockmueller@med.uni-muenchen.de \\ Martin Pec \\ martin.pec@uniba.sk \\ Mehdi Shakibaei \\ mehdi.shakibaei@med.uni-muenchen.de \\ Frank A. Giordano \\ frank.giordano@ukbonn.de \\ Dietrich Büsselberg \\ dib2015@qatar-med.cornell.edu
}

1 Department of Medical Biology, Jessenius Faculty of Medicine, Comenius University in Bratislava, 03601 Martin, Slovakia

2 Department of Obstetrics and Gynecology, Jessenius Faculty of Medicine, Comenius University in Bratislava, 03601 Martin, Slovakia

3 Biomedical Centre Martin, Jessenius Faculty of Medicine in Martin, Comenius University in Bratislava, Mala Hora 4D, 03601 Martin, Slovakia

4 Weill Cornell Medicine-Qatar, Education City, Qatar Foundation, Doha 24144, Qatar

5 Department of Pathology, St. Elizabeth Cancer Institute Hospital, 81250 Bratislava, Slovakia

6 Department of Anatomy, Jessenius Faculty of Medicine, Comenius University in Bratislava, 03601 Martin, Slovakia

7 Musculoskeletal Research Group and Tumor Biology, Chair of Vegetative Anatomy, Faculty of Medicine, Institute of Anatomy, Ludwig-Maximilian-University Munich, Munich, Germany

8 Department of Radiation Oncology, University Hospital Bonn, Rheinische Friedrich-Wilhelms-Universität Bonn, Bonn, Germany

9 Predictive, Preventive and Personalised (3P) Medicine, Department of Radiation Oncology, University Hospital Bonn, Rheinische Friedrich-Wilhelms-Universität Bonn, Bonn, Germany 